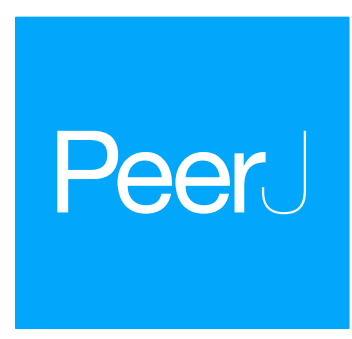

Submitted 27 December 2018 Accepted 27 April 2019 Published 11 June 2019

Corresponding authors Jodi T. Thomas, jodi.thomas@my.jcu.edu.au Erica V. Todd, erica.v.todd@otago.ac.nz

Academic editor Joseph Gillespie

Additional Information and Declarations can be found on page 22

DOI 10.7717/peerj.7032

Copyright

2019 Thomas et al.

Distributed under Creative Commons CC-BY 4.0

\section{Conservation and diversity in expression of candidate genes regulating socially- induced female-male sex change in} wrasses

\author{
Jodi T. Thomas ${ }^{1,2}$, Erica V. Todd ${ }^{2}$, Simon Muncaster ${ }^{3}$, P Mark Lokman ${ }^{4}$, Erin \\ L. Damsteegt ${ }^{4}$, Hui Liu ${ }^{2}$, Kiyoshi Soyano ${ }^{5}$, Florence Gléonnec ${ }^{2,6}$, Melissa S. Lamm ${ }^{7}$, \\ John R. Godwin ${ }^{7}$ and Neil J. Gemmell ${ }^{2}$
${ }^{1}$ ARC Centre of Excellence for Coral Reef Studies, James Cook University, Townsville, Queensland, Australia
${ }^{2}$ Department of Anatomy, University of Otago, Dunedin, Otago, New Zealand
${ }^{3}$ Faculty of Primary Industries, Environment and Science, Toi Ohomai Institute of Technology, Tauranga, Bay of Plenty, New Zealand
${ }^{4}$ Department of Zoology, University of Otago, Dunedin, Otago, New Zealand
${ }^{5}$ Institute for East China Sea Research, Organization for Marine Science and Technology, Nagasaki University, Taira-machi, Nagasaki, Japan
${ }^{6}$ BIOSIT - Structure Fédérative de Recherche en Biologie-Santé de Rennes, Université Rennes I, Rennes, France ${ }^{7}$ Department of Biological Sciences and WM Keck Center for Behavioral Biology, North Carolina State University, Raleigh, NC, United States of America

\section{ABSTRACT}

Fishes exhibit remarkably diverse, and plastic, patterns of sexual development, most striking of which is sequential hermaphroditism, where individuals readily reverse sex in adulthood. How this stunning example of phenotypic plasticity is controlled at a genetic level remains poorly understood. Several genes have been implicated in regulating sex change, yet the degree to which a conserved genetic machinery orchestrates this process has not yet been addressed. Using captive and in-the-field social manipulations to initiate sex change, combined with a comparative qPCR approach, we compared expression patterns of four candidate regulatory genes among three species of wrasses (Labridae) — a large and diverse teleost family where female-to-male sex change is pervasive, socially-cued, and likely ancestral. Expression in brain and gonadal tissues were compared among the iconic tropical bluehead wrasse (Thalassoma bifasciatum) and the temperate spotty (Notolabrus celidotus) and kyusen (Parajulus poecilepterus) wrasses. In all three species, gonadal sex change was preceded by downregulation of cyp19ala (encoding gonadal aromatase that converts androgens to oestrogens) and accompanied by upregulation of amh (encoding anti-müllerian hormone that primarily regulates male germ cell development), and these genes may act concurrently to orchestrate ovary-testis transformation. In the brain, our data argue against a role for brain aromatase (cyp19a1b) in initiating behavioural sex change, as its expression trailed behavioural changes. However, we find that isotocin ( $i t$, that regulates teleost socio-sexual behaviours) expression correlated with dominant male-specific behaviours in the bluehead wrasse, suggesting it upregulation mediates the rapid behavioural sex change characteristic of blueheads and other tropical wrasses. However, it expression was not sex-biased in temperate spotty and kyusen wrasses, where sex change is more protracted and social groups may be less tightly-structured. Together, these findings 
suggest that while key components of the molecular machinery controlling gonadal sex change are phylogenetically conserved among wrasses, neural pathways governing behavioural sex change may be more variable.

Subjects Aquaculture, Fisheries and Fish Science, Developmental Biology, Evolutionary Studies, Genetics, Marine Biology

Keywords Protogynous sex change, Bluehead wrasse, Spotty wrasse, Kyusen wrasse, Quantitative real-time PCR, Sex-biased gene expression, cyp19a1a, cyp19a1b, amh, Isotocin

\section{INTRODUCTION}

Most animals irreversibly differentiate as either male or female, yet some species exhibit remarkable sexual plasticity. This is true for teleost fishes, the only vertebrate lineage to display sequential hermaphroditism, in which individuals begin life as one sex but can change to the opposite sex sometime later in their life cycle (Munday, Buston \& Warner, 2006; Devlin \& Nagahama, 2002). Sex change is typically cued by changes in social structure or by reaching a threshold age or size (Shapiro \& Lubbock, 1980; Lee et al., 2001), and characteristically involves radical changes in behaviour, external colouration and gonadal anatomy (Warner \& Swearer, 1991; Todd et al., 2016). Three patterns are observed; protogyny (female-to-male), protandry (male-to-female), and bidirectional sex change (Warner, 1984). Protogyny is most common, although the widespread and patchy distribution of sequential hermaphroditism across the teleost phylogeny implies multiple evolutionary origins and frequent transitions to and from gonochorism (stable separate sexes) (Mank, Promislow \& Avise, 2006).

Despite significant research effort, the genetic cascades that orchestrate sex change remain elusive (Todd et al., 2016). Numerous genes involved in vertebrate sexual development have been investigated for their potential roles in sex change (Todd et al., 2016). Genes that exhibit expression changes early on in sex change are of particular interest as proximal molecular regulators of the process. One such gene is cyp19a1a, encoding the aromatase enzyme that converts testosterone (T) to $17 \beta$-estradiol (E2) in the female gonad to maintain ovarian function (Devlin \& Nagahama, 2002; Tchoudakova \& Callard, 1998). Aromatase expression is rapidly arrested in transitioning females and this occurs in parallel with a sharp decline in plasma E2 levels and the onset of ovarian atresia (Nakamura et al., 1989). Treatment with aromatase inhibitors reliably induces complete sex reversal in teleosts, whereas co-administration with E2 is preventative (Higa et al., 2003; Nozu, Kojima \& Nakamura, 2009; Bhandari et al., 2005; Kroon \& Liley, 2000). Thus, arrested cyp19a1a expression may initiate gonadal sex change in protogynous species by interrupting a positive E2 feedback loop that in fishes maintains both feminising gene expression and ovarian function (Todd et al., 2016; Guiguen et al., 2010).

The most well-studied potential initiator of the male-specific expression pathway in sex-changing species is $d m r t 1$, a gene that encodes a transcription factor critical for promoting male gonadal development in animals as diverse as flies and humans (Herpin $\&$ Schartl, 2011a). A paralogue of $d m r t 1$ (dmy) has also become the male sex-determining 
gene in several fish species (Matsuda et al., 2002; Nanda et al., 2002; Chen et al., 2014). However, in protogynous hermaphrodites studied to date, changes in $d m r t 1$ expression regularly appear downstream of other genes, suggesting that $d m r t 1$ may be more important in progressing rather than initiating sex change (Nozu et al., 2015; Todd et al., 2018).

Anti-Müllerian hormone, Amh, a multifunctional member of the transforming growth factor-ß(TGF-ß) family, also plays a key role in regulating germ cell development in vertebrates, especially in males (Josso, Di Clemente \& Gouédard, 2001; Siegfried, 2010; Sekido \& Lovell-Badge, 2013). Amh is the male-determining factor in Patagonian pejerrey (Odontesthes hatcheri) (Hattori et al., 2012) and Nile tilapia (Oreochromis niloticus) (Li et al., 2015), while the Amh receptor, Amhr2, determines maleness in several species of Takifugu pufferfish (Kamiya et al., 2012). A transcriptome-wide expression analysis of bluehead wrasse found $a m h$ and $a m h r 2$ to be the earliest male-pathway genes upregulated during female to male sex change, concurrent with arrested expression of cyp19a1a and prior to the appearance of male tissues (Todd et al., 2018). Expression of amh also increased during early protogynous sex change in ricefield eel (Monopterus albus) (Hu et al., 2015), and decreased during protandrous sex change in Red Sea clownfish (Amphiprion bicinctus) (Casas et al., 2016). Therefore, Amh is emerging as a key initiator of maleness in gonochoristic and sex-changing fish.

Most studies focus on gonadal gene expression, yet social cues for sex change are visual and induce rapid neurochemical changes in the brain to initiate behavioural responses that precede, and likely trigger, gonadal changes (Larson, Norris \& Summers, 2003; Semsar \& Godwin, 2003; Godwin \& Thompson, 2012; Lamm et al., 2015). Teleost fishes are unique in having a duplicated, brain-specific paralogue of the aromatase gene, cyp19a1b, responsible for local oestrogen production that plays a key role in brain sexualisation (Diotel et al., 2010). Paralleling gonadal cyp19a1 a activity, forebrain cyp19a1b expression is downregulated in transitioning female bluehead wrasse (Todd et al., 2018). Treatment with exogenous E2 also stimulates cyp 19a1b expression and prevents behavioural sex change in this species (Marsh-Hunkin et al., 2013).

A further gene of growing interest is isotocin (it) (Liu et al., 2016; Todd et al., 2017). Homologous to mammalian oxytocin, it appears to regulate teleost sociosexual behaviours (Goodson \& Bass, 2000; Thompson \& Walton, 2004; O'Connell, Matthews \& Hofmann, 2012; Reddon et al., 2014; Reddon et al., 2012; Hellmann et al., 2015; Donaldson \& Young, 2008). Transcriptomic analyses in the bluehead wrasse have found forebrain it expression to be specific to terminal-phase males, implicating it in social dominance and sex change (Liu et al., 2015).

Protogyny is most pervasive, and likely ancestral, in labrid fishes (Erisman et al., 2013). The Labridae are the second largest marine fish family, encompassing the wrasses, parrotfish and hogfish with over 500 species in 70 genera (Baliga \& Law, 2016; Westneat \& Alfaro, 2005). Protogyny is best studied in wrasses, which present a powerful model to study the evolution and functioning of sex change and explore the degree to which molecular control of this process is conserved. Labrids have a characteristic lek-like mating system, and are often diandric with two colour morphs; initial phase (IP) individuals consist of similarly coloured females and less abundant primary males (female-mimics), which can 

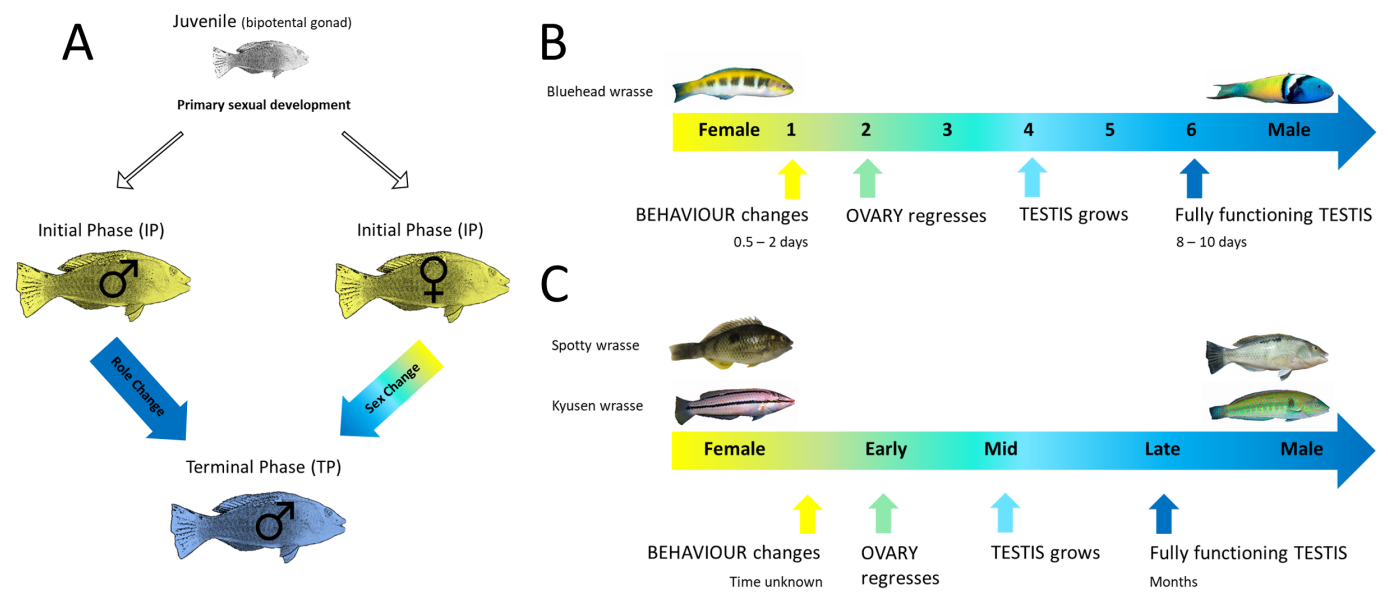

Figure 1 Life history of protogynous wrasses. (A) Generalised life cycle of protogynous fishes. Juveniles with a bipotential gonad undergo primary sexual development as either initial phase (IP) females or males. Terminal phase (TP) males develop via sex change by IP females, or role change by IP males, following appropriate social cues. Figure adapted from Todd et al. (2017). (B) Progression of sex change in bluehead wrasse which is classified into 6 stages as previously described (Nakamura et al., 1989), and occurs remarkably fast; behavioural change occurs within 0.5-2 days and complete ovary-to-testis transformation is completed in 8-10 days (Warner \& Swearer, 1991). (C) Progression of sex change in spotty and kyusen wrasses which is classified into early, mid and late stages, broadly corresponding to stages $2-3$, 4 and 5-6 in the bluehead wrasse, respectively. Sex change in these seasonal breeders may take up to several months. Figure adapted from Liu et al. (2016). Bluehead wrasse male image open access by Evan D'Alessandro, courtesy Oregon State University; bluehead wrasse female image open access; spotty male image by Jodi Thomas; spotty female image by Simon Muncaster; kyusen images with permission by Keoki Stender http: //www.marinelifephotography.com.

Full-size DOI: 10.7717/peerj.7032/fig-1

sex or role change respectively, to replace the dominant terminal phase (TP) male upon its death or removal (Fig. 1A) (Warner \& Swearer, 1991; Kazancioğlu \& Alonzo, 2010). Sex change occurs year-round in tropical wrasses, but follows a discreet spawning season in temperate species and occurs more slowly and from an already regressed ovary with low oestrogen production (Muncaster, Norberg \& Andersson, 2013). Thus, an important question is whether aromatase downregulation plays a pivotal role initiating sex change in both tropical and temperate wrasses.

In this study, four candidate genes are evaluated as proximate regulators of protogynous sex change, in the gonad (cyp19a1a, amh) and brain (cyp19a1b, it), using a comparative approach across three diandric protogynous wrasses (Figs. 1B and 1C): the tropical Caribbean bluehead wrasse (Thalassoma bifasciatum), and the temperate New Zealand spotty wrasse (Notolabrus celidotus) and Japanese kyusen wrasse (Parajulis poecilepterus). We sought to (1) investigate whether evolutionarily conserved molecular mechanisms underlie protogynous sex change in wrasses, and (2) examine potential differences among tropical versus temperate species. Specifically, we were interested in the importance of changes in aromatase expression in initiating gonadal sex change and isotocin expression in initiating behavioural sex change in temperate species, in which sex change proceeds from post-spawning, already regressed ovaries, and in which social hierarchies may be less tightly structured. 


\section{MATERIALS \& METHODS}

\section{Sample collection \\ Experiment 1: social induction of sex change in wild bluehead wrasse}

Sex change was induced in wild bluehead wrasse social groups by social manipulation on patch reefs off the coast of Key Largo, Florida, between May and June 2014. These experiments are described in detail elsewhere (Liu et al., 2015). Three individuals representing each of six stages of sex change (described below), plus control females, IP males and TP males were used in the current study. Experiments were conducted in accordance with approval from North Carolina State University (12-069-0).

\section{Experiment 2: social induction of sex change in captive spotty wrasse}

A social manipulation experiment was conducted to induce sex change in captive female spotty wrasse between August and December 2016, towards the end of the spawning season and overlapping the period when sex change is documented in the wild (NovemberMay) (Jones, 1980). Fish were collected from Tauranga Harbour $\left(37^{\circ} 40^{\prime} 29^{\prime} \mathrm{S} ; 176^{\circ} 10^{\prime} 20^{\prime \prime} \mathrm{E}\right)$ by hook and line. Fifty IP fish were evenly distributed into groups across ten $500 \mathrm{~L}$ tanks containing recirculating seawater (35 ppt). IP individuals ranged from $149 \mathrm{~mm}-217$ mm total length (TL) and were distributed such that each tank contained a hierarchy of different sized fish plus a single TP male (size range $222 \mathrm{~mm}-247 \mathrm{~mm}$ TL). Ambient light was available through semi-translucent roof panels and was supplemented with overhead fluorescent lighting (Sylvania Cool White De Luxe, Osram Sylvania Ltd) on a 12:12 light:dark daily cycle. Fish were fed a combination of thawed mussel, Perna canaliculus, and commercial marine fish feed (Ridley Aquafeed, Ridley Corporation) to satiation three times per week.

Following an acclimation period of three weeks, TP males were removed from five of the 10 tanks (day 0), creating a permissive social environment for sex change. As a control on day 0 , the largest IP fish were removed from each of the control tanks, and also served as a baseline. Subsequently, the largest IP fish per tank was removed at day 30, 50, 60, 65, and 66 post TP male removal. Fish were immediately anaesthetised in an aerated bath containing $6 \mathrm{ml} \mathrm{L}^{-1}$ 2-phenoxyethanol (Sigma Aldrich) before being euthanized by decapitation. A gonad section (mid-section of one paired gonad) and the whole brain were preserved in RNAlater (Invitrogen ${ }^{\mathrm{TM}}$, Thermo Fisher Scientific), chilled at $-18^{\circ} \mathrm{C}$ for $24 \mathrm{~h}$, then stored at $-80{ }^{\circ} \mathrm{C}$ until RNA extraction. An additional gonad section (mid-section of second gonad) was fixed in either Bouin's (testis and transitional gonads) or neutral-buffered formalin (ovary), and subsequently dehydrated by submersion in ethanol (70, 80, 96 and $100 \%$ ) followed by xylene. Gonadal tissue was paraffin-embedded and $3 \mu \mathrm{m}$ sections were stained with hematoxylin and eosin (H\&E) for light microscopy (New Zealand Veterinary Pathology, Hamilton) to determine sexual status. Fish were collected with approval from the New Zealand Ministry of Primary Industries (593-3) and experiments were conducted in accordance with approval from the New Zealand National Animal Ethics Advisory (2015_02). 


\section{Survey 1: opportunistic sampling of spotty wrasse}

Seven fish were caught by hook and line off Portobello Wharf, Dunedin, New Zealand, and an additional seven fish were obtained from the nearby New Zealand Marine Studies Centre, during the non-breeding season between March and May 2013. Fish were euthanized with an overdose of benzocaine $(0.3 \mathrm{~g} / \mathrm{L})$ and the brain and gonads dissected immediately. One gonad and the whole brain were preserved in RNAlater (Life Technologies, Inc.) on ice, before storage at $-80{ }^{\circ} \mathrm{C}$ until RNA extraction. The second gonad was preserved in $10 \%$ formalin for histological analysis. Gonadal tissue was paraffin-embedded and $5 \mu \mathrm{m}$ sections were stained with H\&E to determine sexual status (Histology Services Unit, University of Otago). Experiments were conducted in accordance with approval from the New Zealand National Animal Ethics Advisory (92-10).

\section{Survey 2: wild-caught kyusen wrasse}

Fish were caught by hook and line from Oomura Bay $(n=2)$ and Chijiwa Bay $(n=29)$, Kyushu Island, Japan, at the end of the breeding season between September and November 2010. Fish were euthanized with an overdose of 2-phenoxyethanol and the brain and gonads dissected out immediately. A gonad section and the brain were preserved in RNAlater (Life Technologies, Inc.) on ice, or flash frozen in liquid nitrogen, before storage at $-80{ }^{\circ} \mathrm{C}$ until RNA extraction. An additional gonad section was preserved in Bouin's fixative for histological analysis. Gonadal tissue was paraffin-embedded and $5 \mu \mathrm{m}$ sections were stained with $H \& E$ to determine sexual status. Experiments were conducted in accordance with approval from the Animal Care and Use Committee of the Institute for East China Sea Research, Nagasaki University, Japan (\#15-06).

\section{Histological analysis of the gonad}

For bluehead wrasse, transitioning fish were grouped into six stages as per the classification system of Nakamura et al. (1989). As seasonal breeders, female spotty and kyusen wrasses were classified as either non-breeding female (NBF) or breeding female (BF), depending on the presence of maturing oocytes. Transitioning animals were classified into early transitional (ET), mid transitional (MT) or late transitional (LT) stages (see Table S1). ET fish were distinguished from NBF by having elevated oocyte atresia, including degenerating previtellogenic oocytes, and typically contained nests of gonial germ cells (presumed to later become spermatogonia), masses of stromal cells and cellular debris (also present as yellow-brown bodies) as observed in other ET protogynous species (Muncaster, Norberg $\&$ Andersson, 2013; Bhandari et al., 2003) (Table S1). In spotty and kyusen wrasse, the ET, MT and LT stages broadly correspond to stages 2-3, 4 and 5-6 as outlined by Nakamura et al. (1989) and used to classify bluehead wrasse.

\section{RNA extraction}

Due to samples being obtained from several sources and processed at different times, different extraction protocols were used and are summarised in Table S2. For spotty and bluehead brain samples, the hindbrain (corpus cerebelli, pons, and medulla) was removed prior to RNA extraction. The forebrain/midbrain was prioritised for analysis as it is 
expected to contain key neural circuits involved in socially regulated sex change (O'Connell \& Hofmann, 2011).

\section{Reverse transcription}

Total RNA was quantified by Qubit 2.0 Fluorometer (Qubit RNA HS Assay Kit, Life Technologies), and RNA purity was measured by spectrophotometer (NanoDrop 2000c, ThermoFisher Scientic). Bluehead RNA was reverse transcribed in a Mastercycler Pro $\mathrm{S}$ thermal cycler (Eppendorf) with the following protocol: $37^{\circ} \mathrm{C}(15 \mathrm{mins}), 85^{\circ} \mathrm{C}(5 \mathrm{~s}), 4^{\circ} \mathrm{C}$ until removal. For spotty and kyusen, reverse transcription reactions were performed in a SureCycler 8800 (Agilent Technologies) with the following protocol: $25^{\circ} \mathrm{C}$ (10 mins), $37{ }^{\circ} \mathrm{C}(120 \mathrm{~min}), 85^{\circ} \mathrm{C}(5 \mathrm{mins}), 4{ }^{\circ} \mathrm{C}$ until removal. Further details are provided in Table S2.

\section{Determination of gene sequences}

Preliminary sequence data for four target genes (cyp19a1a, amh, cyp19a1b, and it) and three potential reference genes (ef1a, 18S, and $g 6 p d)$ were obtained from transcriptome assemblies for bluehead wrasse (Liu et al., 2015) and spotty wrasse (EV Todd \& NJ Gemmell, 2015, unpublished data) representing gonad and brain tissues. Bluehead wrasse it and efla sequences were previously published (Genbank MF279538.1 and MF279537.1, respectively) (Todd et al., 2017). Contigs were partially verified using PCR. PCR primers were designed against the contig sequence for each gene in bluehead and spotty wrasse using Primer3 (Untergasser et al., 2012), and are shown in Table S3. Reactions (20 $\mu \mathrm{L})$ contained 10 ng cDNA, $1 \times$ MyTaq reaction buffer (Bioline), $1 \times$ MyTaq DNA Polymerase (Bioline), and $0.5 \mu \mathrm{M}$ forward and reverse primers. Reactions were run in a Mastercycler Pro $S$ thermal cycler (Eppendorf) with the following protocol: $95{ }^{\circ} \mathrm{C}(3 \mathrm{mins})$ followed by 35 cycles of $95^{\circ} \mathrm{C}(30 \mathrm{~s})$, annealing at $5^{\circ} \mathrm{C}$ below primer melting temperature (see Table S3) (30 s), and $72{ }^{\circ} \mathrm{C} \mathrm{(45} \mathrm{s),} \mathrm{with} \mathrm{a} \mathrm{final} \mathrm{extension} \mathrm{at} 72{ }^{\circ} \mathrm{C}$ ( $\left.15 \mathrm{mins}\right)$. PCR products were visualised by electrophoresis through a $1 \%$ agarose gel using SYBR Safe DNA Gel Stain (Invitrogen). Amplicons of expected sizes were gel-extracted using a NucleoSpin gel and PCR clean-up kit (Macherey-Nagel). Extracted products were Sanger sequenced (Genetic Analysis Services, Department of Anatomy, University of Otago) in both directions using the respective PCR primers. For kyusen wrasse, bluehead wrasse PCR primers were used to determine partial gene sequences. Forward and reverse amplicons were aligned to create a consensus kyusen sequence for each gene in Geneious R10 (Kearse et al., 2012). Primers for amh and it did not amplify kyusen DNA, however qPCR primers designed for bluehead wrasse were successful in kyusen (see Table S4).

\section{Quantitative real-time PCR}

For each gene, species-specific primers were designed nested within the verified partial gene sequences in Primer3 (see Table S4). Primers were designed to cross exon-exon boundaries to avoid amplifying residual contaminating DNA.

Quantitative real-time PCR (qPCR) was used to measure mRNA levels for each gene in either gonad or brain using the QuantStudio 5 Real-Time PCR system (ThermoFisher). All samples, including standards and negative controls, were run in duplicate (bluehead 
wrasse) or triplicate (all other samples) in a 96-well plate. An inter-plate calibrator (cDNA from 6 randomly chosen individuals) was run in triplicate for each spotty qPCR assay.

Target gene DNA previously obtained by PCR was used to create standard curves consisting of seven 10-fold dilutions. Reactions $(10 \mu \mathrm{L}$ ) contained $20 \mathrm{ng}$ cDNA (except for 18S, 0.2 ng), $1 \mu \mathrm{M}$ forward and reverse primers, $1 \times \mathrm{SYBR}^{\circledR}$ Premix Ex Taq ${ }^{\mathrm{TM}}$ II (Tli RNaseH Plus) (Takara), and $1 \times$ ROX reference dye (Takara). Bluehead wrasse samples were run without ROX reference dye. Cycling conditions were $95^{\circ} \mathrm{C}(2 \mathrm{mins})$ followed by 40 cycles of $95^{\circ} \mathrm{C}$ (5 s), annealing temperature (see Table S4) (10 s), and $72^{\circ} \mathrm{C}(5 \mathrm{~s})$. Melt curve analysis was run to verify the production of a single product which was then confirmation-sequenced (Genetic Analysis Services, Department of Anatomy, University of Otago). Further qPCR details are supplied in a MIQE table (see Table S5).

\section{Statistical analysis}

Due to non-normality of the raw qPCR data, the non-parametric Kruskal-Wallis test was used, followed by post hoc comparisons using Dunns tests, with Benjamini Hochberg correction for multiple comparisons, in R ( $R$ Core Team, 2014) (Data S1 and S2). Expression of ef1 $a, 18 S$ and $g 6 p d$ as well as the geometric mean of all possible combinations, was tested for use as reference genes. Data were normalised using reference gene(s) whose expression was not significantly affected by sex and that showed the flattest expression profile across sexes (see Table S6 for chosen reference genes). Overall, data normalisation had minimal effect on the trend of the results except for spotty wrasse survey 1 , in which normalisation masked otherwise clear sex-specific trends for both gonadal genes (Table S6, Figs. S1E and S1F). Therefore, results are presented for un-normalised data. Results for normalised data are available as supplemental materials (see Fig. S1 for gonadal genes and Fig. S2 for brain genes). For each experiment, graphed results are presented as expression relative to control females (i.e., all other sample quantities are expressed as an $n$-fold difference relative to the control female group).

\section{Phylogenetic analysis}

Robust fine-scale phylogenies support comparative analyses of labrids (Baliga \& Law, 2016). However, as these do not yet include the spotty wrasse, we undertook phylogenetic analyses to resolve the relationship of spotty wrasse to the bluehead and kyusen wrasses. Sequences of the $12 \mathrm{~S}$ and $16 \mathrm{~S}$ mitochondrial ribosomal genes were produced for all three species, using PCR primers from Westneat \& Alfaro (2005), and they were combined with sequences from 296 labrid taxa analysed in Baliga \& Law (2016) (kindly provided by Dr. Vikram Baliga). Genomic DNA was extracted from ovary (kyusen and bluehead wrasse) and liver (spotty) samples using a standard lithium-chloride protocol (Gemmell \& Akiyama, 1996). Mitochondrial ribosomal genes $12 S$ and $16 S$ were PCR-amplified using reactions $(20 \mu \mathrm{L})$ containing $10 \mathrm{ng} \mathrm{DNA}, 1 \times \mathrm{NH}_{4}$ reaction buffer (Bioline), $1 \times$ BIOTAQ DNA Polymerase (Bioline), $2 \mathrm{mM} \mathrm{MgCl}_{2}$ solution, $1 \mathrm{mM} \mathrm{dNTP}$ mix, and $1 \mu \mathrm{M}$ forward and reverse primers. Reactions were run in a Sure Cycler 8800 (Agilent Technologies) with the following protocol: $94{ }^{\circ} \mathrm{C}(2 \mathrm{mins})$ followed by 30 cycles of $94{ }^{\circ} \mathrm{C}(30 \mathrm{~s}), 60{ }^{\circ} \mathrm{C}(12 \mathrm{~S})$ or $49{ }^{\circ} \mathrm{C}(16 \mathrm{~S})(30 \mathrm{~s})$, and $72{ }^{\circ} \mathrm{C}(55 \mathrm{~s})$, with a final extension at $72{ }^{\circ} \mathrm{C}(2 \mathrm{mins})$. PCR 
products were visualised by electrophoresis through a $1 \%$ agarose gel using SYBR Safe DNA Gel Stain (Invitrogen), purified using AcroPrep Advance 96-well filter plates (Pall Corporation), and Sanger sequenced in both directions using the respective PCR primers (Genetic Analysis Services, Department of Anatomy, University of Otago).

Phylogenetic relationships within the Labridae were reconstructed using Bayesian inference in MrBayes 3.2.6 (Ronquist \& Huelsenbeck, 2003), using the CIPRES Science Gateway v3.3. $12 S$ and $16 S$ sequences were concatenated following determination of the best-fit model of nucleotide substitution for each gene (GTR + I + G, based on AIC, BIC and DT scores) in jModelTest 2.0 (Darriba et al., 2012) (Data S3). A partitioned analysis was carried out with four separate runs, each from a different random starting tree. Default settings were used as priors, and four Markov chains were sampled every 10, 000 generations over 71.2 million Markov chain Monte Carlo generations. Convergence was supported by the average standard deviation of split frequencies of independent runs falling below 0.01 . Bayesian posterior probabilities were calculated after discarding the first $25 \%$ of sampled trees burn-in. The $50 \%$ majority rule consensus tree was prepared in FigTree v1.4.3 (http://tree.bio.ed.ac.uk/).

\section{RESULTS}

\section{Labridae phylogeny}

Spotty wrasse was placed with strong statistical support ( $>90 \%$ bootstrap support) within the Pseudolabrines, together with other Notolabrus spp (Fig. 2). This group is resolved as sister to the Labrichthyines and Julidines, which contains the bluehead and kyusen wrasse. Our analysis places the Labrichthyines as sister to the Julidines, as in previous labrid phylogenies (Westneat \& Alfaro, 2005; Cowman, Bellwood \& Van Herwerden, 2009), whereas the Baliga \& Law (2016) topology positions the Labrichthyines within the Julidines.

\section{Sex change}

\section{Experiment 1: social induction of sex change in wild bluehead wrasse}

Social manipulations successfully induced sex change in wild female bluehead wrasses, and form part of whole-transcriptome analyses described elsewhere (Todd et al., 2017; Liu et al., 2015). Three samples representative of each sex change stage, plus control females, TP and IP males were analysed herein (Fig. 3).

\section{Experiment 2: social induction of sex change in captive spotty wrasse}

Removal of TP males readily induced sex change in captive female spotty wrasse (Figs. 4 and 5). Histological analysis revealed that in the manipulated tanks (TP male removed), 15 fish reached ET stage (day $30 n=2$, day $50 n=3$, day $60 n=4$, day $65 n=3$, day $66 n=3$ ), one reached MT stage (day 50), one LT stage (day 50), and one was classified as fully TP male (day 60). Only four females within the manipulated tanks showed no histological signs of sex change upon sampling (day $30 n=2$, day $66 n=2$ ). There was no conclusive evidence of sex change by females in control tanks (TP male present). However, four control females (day $30 n=3$, day $66 n=1$ ) showed evidence of early ovarian atresia indicative of an ET stage, although this may represent normal atresia following the breeding season. Across the 


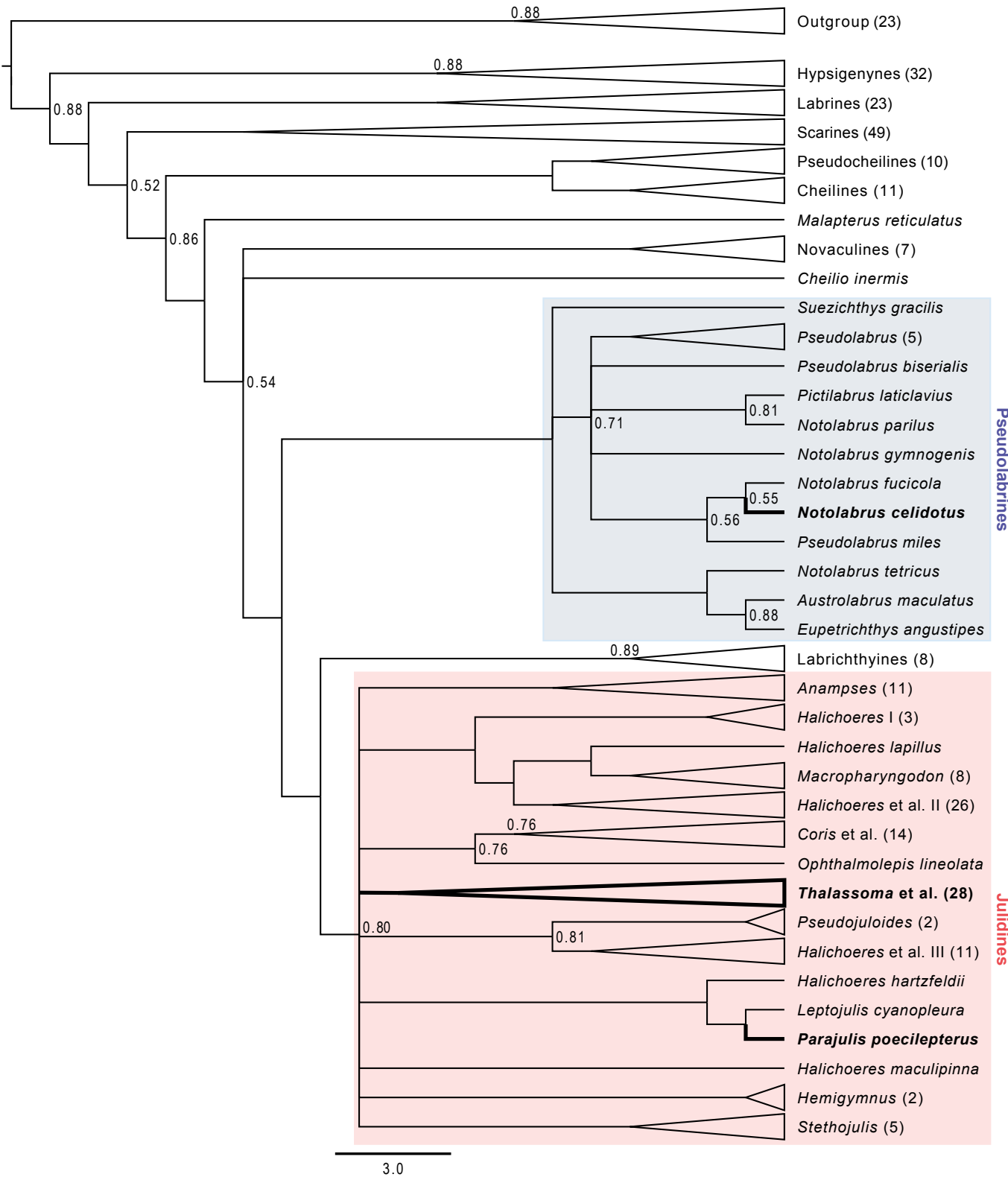

Figure 2 Majority rule consensus tree from Bayesian MCMC analyses. The tree is simplified to show relationships between the bluehead, spotty, and kyusen wrasses. Unlabelled nodes have Bayesian posterior probabilities $>0.90$. Tip labels are the species or genus names, with the number of species sampled in brackets. A triangular tip indicates the clade has been collapsed.

Full-size DOI: 10.7717/peerj.7032/fig-2

entire experiment, five of the original 53 IP fish were found to be IP males after histological analysis.

\section{Survey 1: opportunistic sampling of spotty wrasse}

Among the opportunistically caught spotty wrasse, fish were found at a range of stages (NBF $n=6, \operatorname{ET} n=3, \operatorname{MT} n=2, \operatorname{LT} n=2$, TP male $n=1$ ) (Fig. 5). 

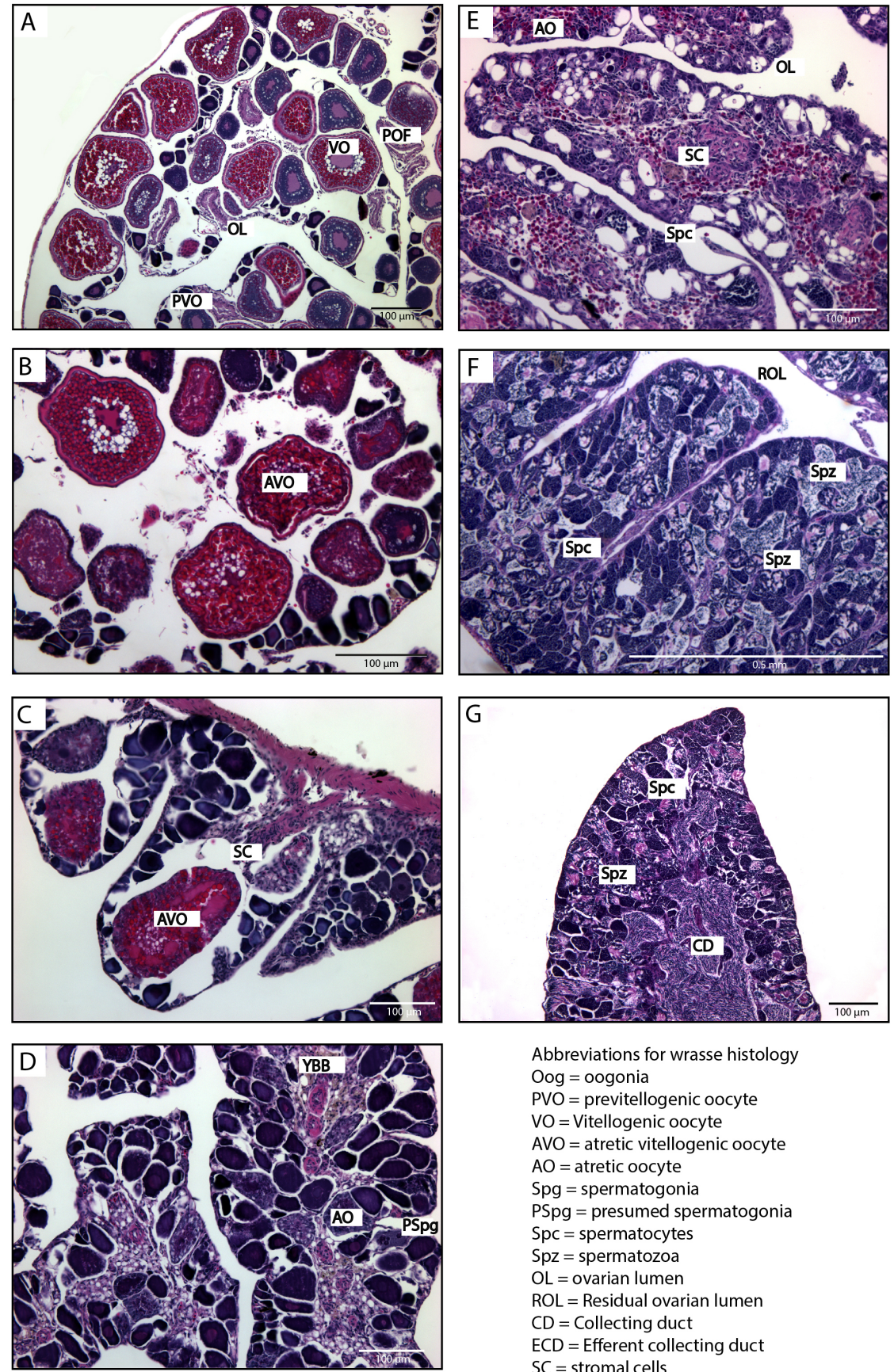

$$
\begin{aligned}
& \text { Abbreviations for wrasse histology } \\
& \text { Oog = oogonia } \\
& \mathrm{PVO}=\text { previtellogenic oocyte } \\
& \text { VO = Vitellogenic oocyte } \\
& \mathrm{AVO}=\text { atretic vitellogenic oocyte } \\
& \mathrm{AO}=\text { atretic oocyte } \\
& \mathrm{Spg}=\text { spermatogonia } \\
& \mathrm{PSpg}=\text { presumed spermatogonia } \\
& \mathrm{SpC}=\text { spermatocytes } \\
& \mathrm{Spz}=\text { spermatozoa } \\
& \mathrm{OL}=\text { ovarian lumen } \\
& \mathrm{ROL}=\text { Residual ovarian lumen } \\
& \mathrm{CD}=\text { Collecting duct } \\
& \mathrm{ECD}=\text { Efferent collecting duct } \\
& \mathrm{SC}=\text { stromal cells } \\
& \mathrm{YBB}=\text { yellow brown bodies } \\
& \mathrm{POF}=\text { Post ovulatory follicle }
\end{aligned}
$$

Figure 3 Histological stages of gonadal sex change in the bluehead wrasse. (A) Stage 1, breeding female with mature ovary containing pre-vitellogenic and vitellogenic oocytes. (B) Stage 2, atresia of vitellogenic oocytes. (C) Stage 3, atresia of pre-vitellogenic and vitellogenic oocytes and clustering of stromal cells. (D) Stage 4, proliferation of presumed spermatogonia. (E) Stage 5, spermatogenesis begins. (F) Stage 6, mature testis with spermatozoa and a residual ovarian lumen. (G) Initial phase male containing spermatozoa, where absence of a residual ovarian lumen suggests this fish has not sex changed and is an initial phase male. Scale bar, $100 \mu \mathrm{m}$ (A, B, C, D, E, G), $0.5 \mathrm{~mm}$ (F). Stages follow the classification of Nakamura et al. (1989). 


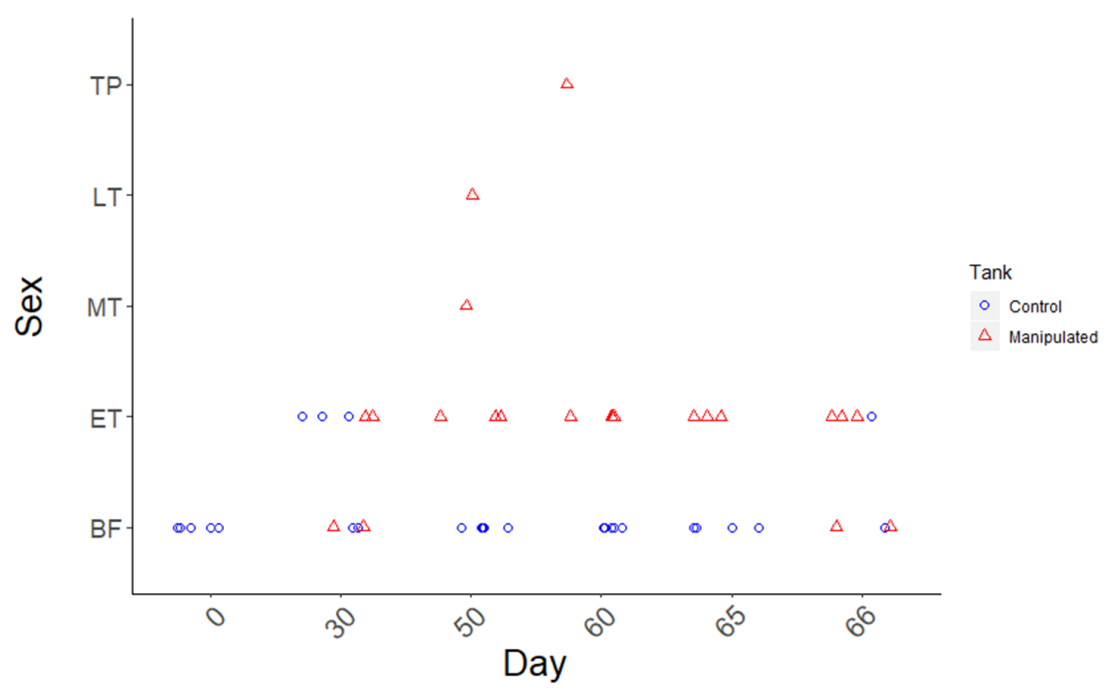

Figure 4 Time course of sex change in the spotty wrasse following social manipulation in captivity (Experiment 2). Points represent the sex change stage of each sampled female on each sampling day. Blue circles are samples from control tanks (TP male present - non-permissive environment), and red triangles from manipulated tanks (TP male removed - permissive environment).

Full-size DOI: $10.7717 /$ peerj.7032/fig-4

\section{Survey 2: wild-caught kyusen wrasse}

Wild-caught kyusen wrasse were mostly females (NBF $n=7)$ and TP males (TP $n=11$ ), plus a few ET females $(n=3)$ and IP males $(n=3)$ (Fig. 6$)$. The ET fish were sampled in late September.

\section{Quantitative real-time PCR Gonad: cyp19a1a}

In all three species, cyp19a1a expression was highest in ovaries and near-zero in TP and IP male testes (Fig. 7). In bluehead and spotty wrasses, cyp19a1a expression decreased across progressive sex change stages.

\section{Experiment 1: social induction of sex change in wild bluehead wrasse}

Sex had a significant effect on cyp19a1a expression $\left(X^{2}(8)=25.08, p<0.01\right)$. At the onset of behavioural sex change (stage 1), a spike in cyp19a1a expression occurred (median 1.8 fold higher than control females (CF)), followed by near zero expression from stage 2 onwards (onset of ovarian atresia). There was a significant difference in the distribution of cyp19a1a expression between control females and TP (median 0.0001-fold that of CF, $p<0.05$ ) and IP males (median 0.00007-fold that of CF, $p<0.05$ ), but not between control females and stages $1-6$. However, there was a clear trend of decreasing expression (Fig. 7).

\section{Experiment 2: social induction of sex change in captive spotty wrasse}

Sex significantly affected cyp19a1a expression $\left(X^{2}(7)=38.35, p<0.0001\right)$. Decreased cyp19a1a expression was first observed among females at the ET stage (median 0.3-fold lower than C BF D0, non-significant; median 0.28 -fold lower than C BF, $p<0.01$ ). The 

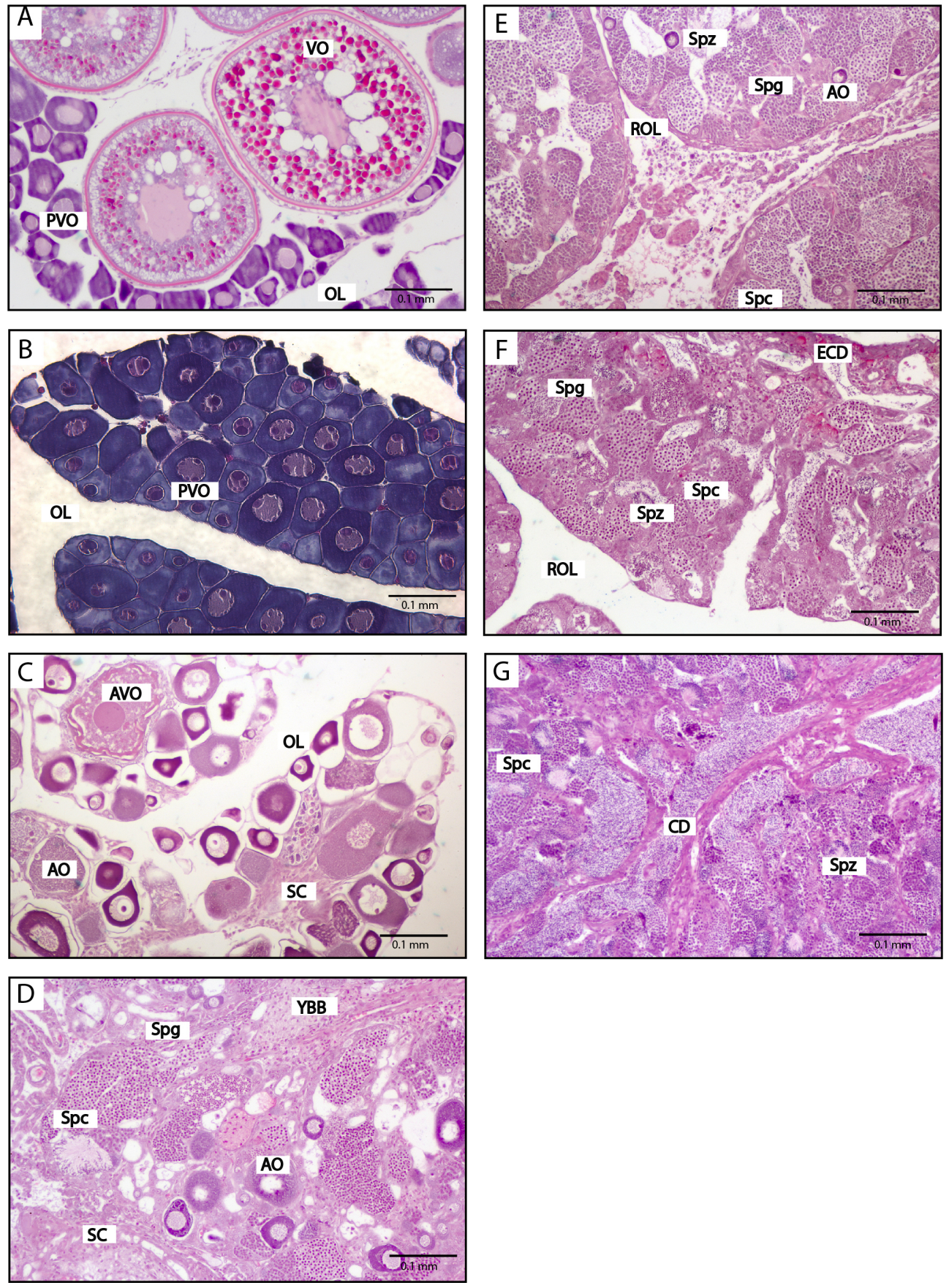

Figure 5 Histological stages of gonadal sex change in the spotty wrasse. (A) Breeding female with previtellogenic and vitellogenic oocytes. (B) Non-breeding female predominated by pre-vitellogenic oocytes. (C) Early transitional; atresia of oocytes and presence of stromal cells. (D) Mid transitional; oocyte numbers diminished and ovarian follicles were largely atretic, with proliferation of spermatogonia. (E) Late transitional; spermatogenic cysts predominate over atretic oocytes. (F) Terminal phase male; mature testis with spermatozoa in cysts arranged into seminiferous tubules with presence of a residual ovarian lumen. (G) Initial phase male containing spermatozoa, where absence of a residual ovarian lumen suggests this fish has not sex changed and is an initial phase male. Scale bar, $0.1 \mathrm{~mm}$. See Fig. 3 for abbreviations.

Full-size DOI: 10.7717/peerj.7032/fig-5 

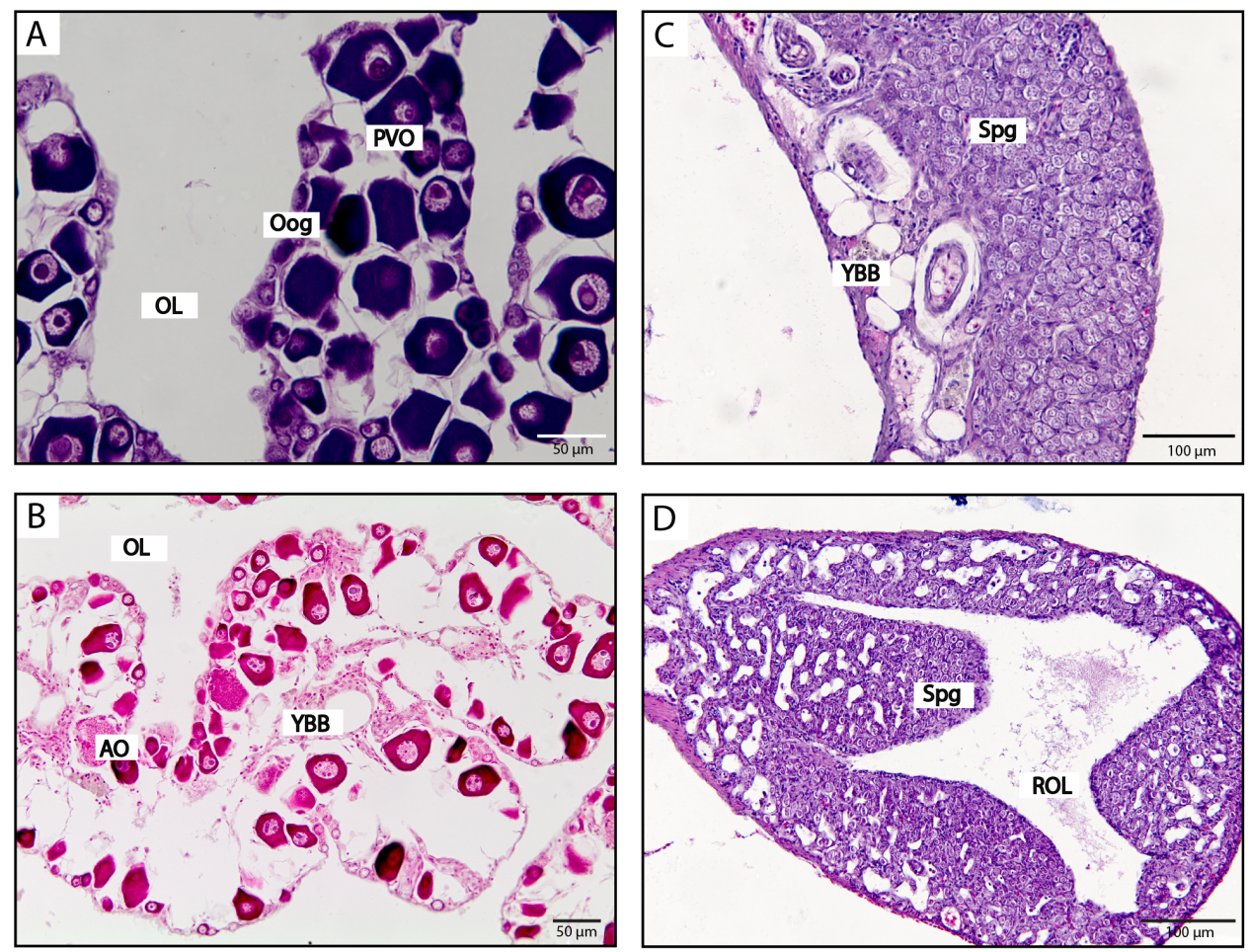

Figure 6 Histological stages of gonadal sex change in the kyusen wrasse. (A) Non-breeding female with pre-vitellogenic oocytes. (B) Early transitional; atretic oocytes and yellow brown bodies. (C) Late transitional; proliferation of spermatogonia. (D) Terminal phase male; mature testis with lobular structure and a residual ovarian lumen. Scale bar, $100 \mu \mathrm{m}$ (A, B), $50 \mu \mathrm{m}$ (C, D). See Fig. 3 for abbreviations.

Full-size DOI: 10.7717/peerj.7032/fig-6

single MT fish had a median cyp19a1a expression 0.25-fold that of C BF D0, while the single LT individual had near-zero cyp19a1a expression (median 0.005-fold that of C BF D0). Distribution of gonadal cyp19a1a expression was significantly reduced in TP and IP male testes compared with ovaries of all control females (median in both males 0.02 -fold that of C BF D0, $p<0.01)$.

\section{Survey 1: opportunistic sampling of spotty wrasse}

Sex did not have a significant effect on cyp19a1a expression $\left(X^{2}(4)=9.23, p=0.06\right)$. However, a clear trend was observed with cyp19ala expression at near-zero levels in MT (median 0.004-fold that of NBFs) and LT stage fish (median 0.03-fold that of NBFs), and in the single TP male (median 0.003-fold that of NBFs). Gonadal cyp19a1a expression in three ET samples ranged from 0.3 to 4.3 -fold higher than that seen among the NBFs.

\section{Survey 2: wild-caught kyusen wrasse}

Sex significantly affected cyp19a1a expression $\left(X^{2}(3)=17.02, p<0.001\right)$. There was no difference in cyp19a1a expression between NBFs and the three samples staged as ET. Although cyp19a1a expression was near-zero in TP and IP males (both median 0.1-fold that of NBF), only TP males showed a significant difference in distribution compared with females $(p<0.01)$. 

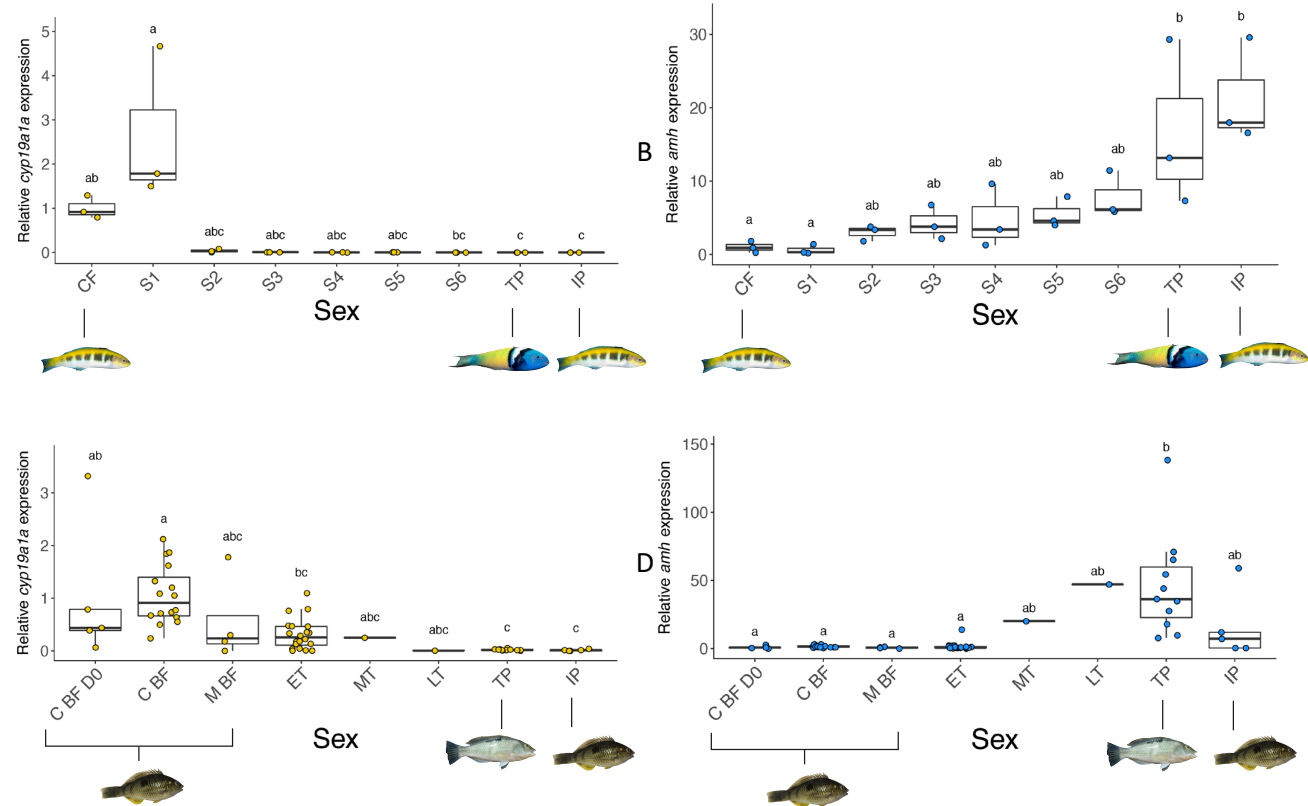

$\mathrm{E}$

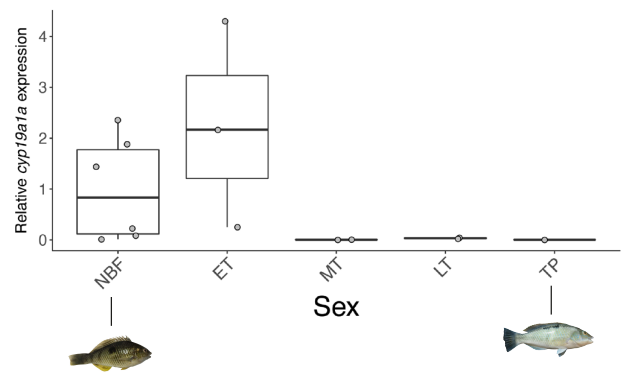

G

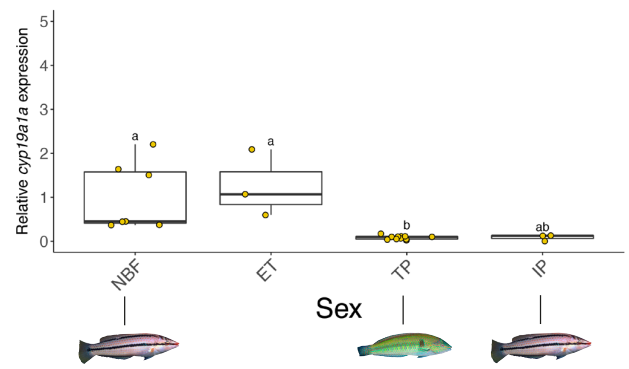

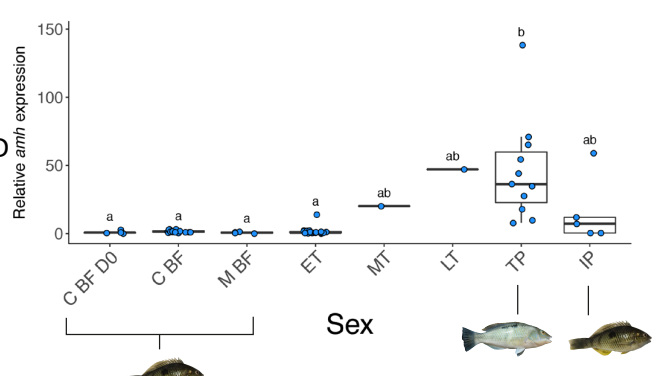
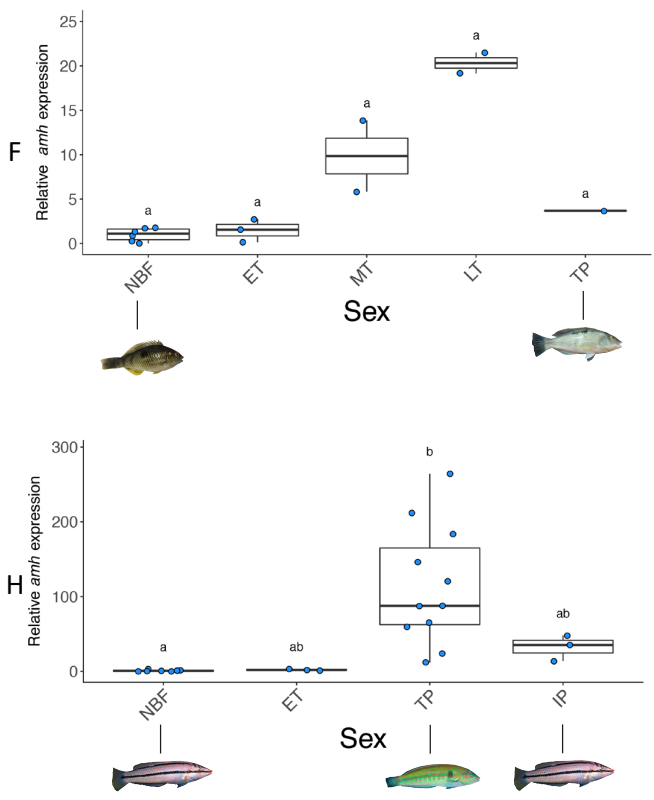

Figure 7 Relative gonadal expression of cyp19a1a (A, C, E, G) and amh (B, D, F, H) mRNA. Expression levels are compared among females, transitioning fish, TP males and IP males. (A, B) Bluehead wrasse induced to change sex in the wild (Experiment 1). (C, D) Spotty wrasse induced to change sex in captivity (Experiment 2). (E, F) Wild-caught spotty wrasse (Survey 1). (G, H) Wild-caught kyusen wrasse (Survey 2). Points represent individual fish. Boxplots represent the median, lower and upper quartile values, and 1.5-fold the interquartile range. Yellow, blue and grey points indicate expression is significantly female-biased, male-biased, and non-significantly different, respectively. Letters denote (continued on next page...)

Full-size DOI: 10.7717/peerj.7032/fig-7 
Figure 7 (...continued)

a significant difference in distribution between groups and 'a' indicates overall significance without significant pairwise differences. Sample sizes: bluehead wrasse $n=3$, all groups; spotty wrasse socially induced to change sex in captivity C BF D0 $n=5, \mathrm{C} \mathrm{BF} n=16, \mathrm{M} \mathrm{BF} n=4$, ET $n=20$, MT $n=1$, LT $n=1$, TP $n=11$, IP $n=5$; spotty wrasse opportunistically caught NBF $n=6$, ET $n=3$, MT $n=2$, LT $\mathrm{n}=2$, TP $n=1$; kyusen wrasse NBF $n=7$, ET $n=3$, TP $n=11$, IP $n=3$. Abbreviations: C BF D0, breeding female from control tank (TP male present) at experiment day 0 ; $\mathrm{C} \mathrm{BF}$, breeding female from control tank (TP male present) removed at progressive time points throughout the experiment; CF, control female; ET, early transitional; IP, initial phase male; LT, late transitional; M BF, breeding female from manipulated tanks (TP male removed) removed at progressive, time points throughout experiment; MT, mid transitional; NBF non-breeding female; S1-6, stages 1-6; TP, terminal phase male. See Fig. 1 legend for photo credits of female and male bluehead, spotty and kyusen wrasses.

\section{Gonad: amh}

Gonadal amh expression showed a pattern opposite to that of cyp19a1a. In all three species, amh expression was near-zero in females and highest in TP males, with a clear trend of increasing expression across sex change (Fig. 7). In all experiments, sex had a significant effect on amh expression (bluehead wrasse: $X^{2}(8)=21.46, p<0.01$, spotty wrasse experiment: $X^{2}(7)=33.18, p<0.0001$, spotty wrasse survey: $X^{2}(4)=9.63, p<0.05$, kyusen wrasse: $\left.X^{2}(3)=18.46, p<0.001\right)$.

\section{Experiment 1: social induction of sex change in wild bluehead wrasse}

Increased amh expression was obvious from stage 2 (median 3-fold higher than $\mathrm{CF}$ ), and steadily increased to a significantly higher distribution in TP (median 13-fold higher than $\mathrm{CF}, p<0.05$ ) and IP males (median 18-fold higher than CF, $p<0.05$ ).

\section{Experiment 2: social induction of sex change in captive spotty wrasse}

There was a trend of progressive amh upregulation beginning in the single fish staged as MT (20-fold higher than C BF D0), continuing in the LT individual (47-fold higher than C $\mathrm{BF}$ D0) and reaching a significantly higher distribution in TP males (median 36-fold higher than C BF D0, $p<0.01$ ). IP males showed a distribution of amh expression intermediate to that of all fish with an intact ovary, and TP males (median 7.23-fold higher than $\mathrm{C} B \mathrm{~B}$ D0).

\section{Survey 1: opportunistic sampling of spotty wrasse}

Despite a significant effect of sex on amh expression, post hoc analysis showed no significant differences between individual sex stages. ET fishes showed similar expression levels to NBFs, while MT and LT stage fish showed a trend of increased amh expression (median 10 -fold and 20-fold higher than NBFs, respectively). Expression of amh in the single TP male was 3.7-fold higher than in NBFs.

\section{Survey 2: wild-caught kyusen wrasse}

ET fish showed similar amh expression to NBFs (median 2-fold higher). TP males had a significantly higher distribution of amh expression (88-fold higher than NBF, $p<0.001$ ), while amh mRNA levels in IP male were intermediate to those of NBFs and TP males (35-fold higher than NBFs). 
A

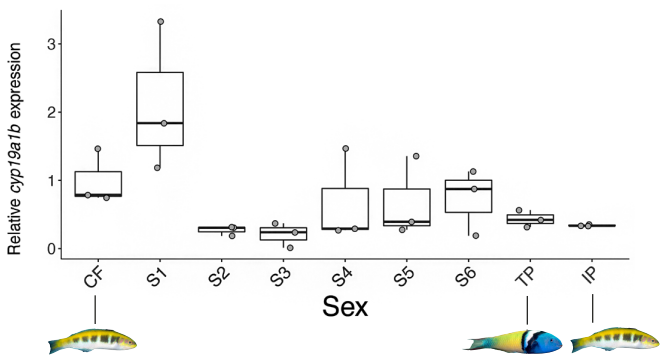

$\mathrm{C}$

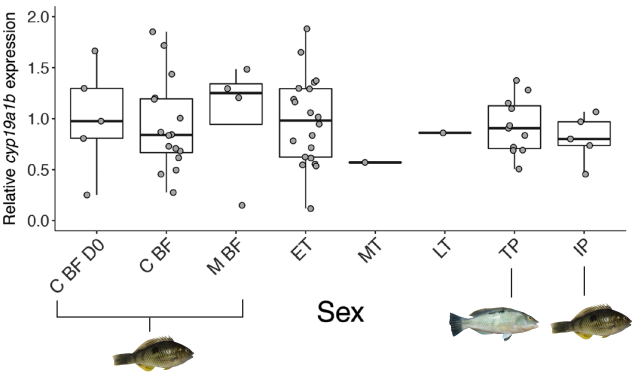

$\mathrm{E}$

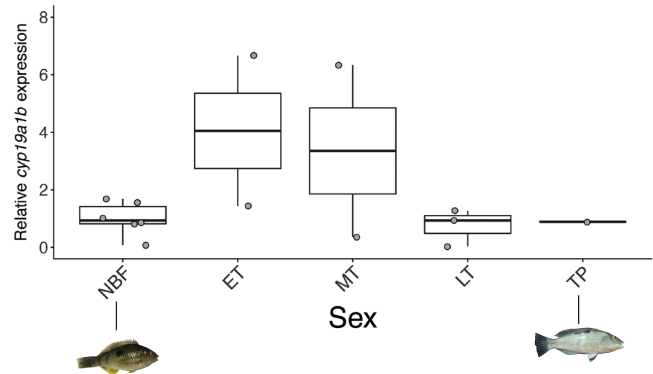

$\mathrm{G}$

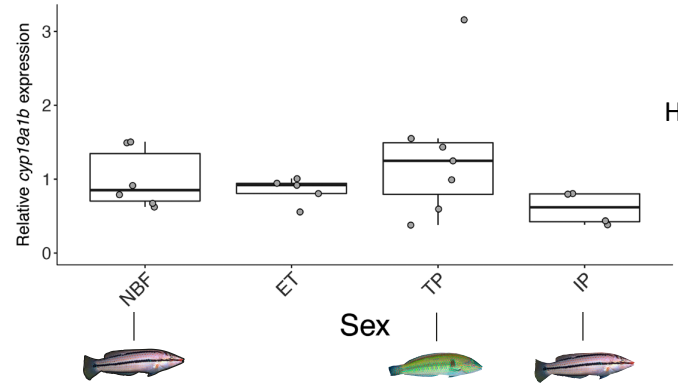

B

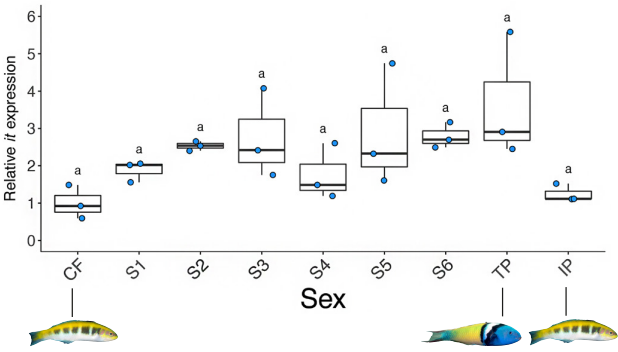

$\mathrm{D}$
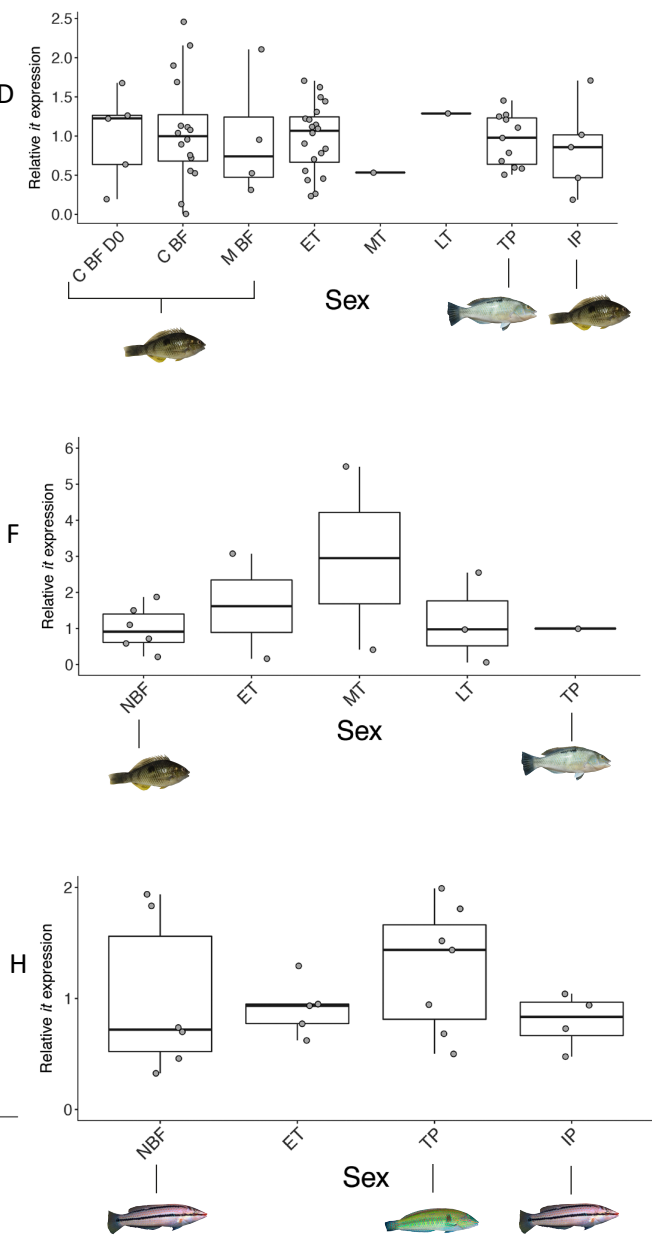

Figure 8 Relative brain expression of cyp19alb (A, C, E, G) and it (B, D, F, H) mRNA. Expression levels are compared among females, transitioning fish, TP males and IP males. (A, B) Bluehead wrasse induced to change sex in the wild (Experiment 1). (C, D) Spotty wrasse induced to change sex in captivity (Experiment 2). (E, F) Wild-caught spotty wrasse (Survey 1). (G, H) Wild-caught kyusen wrasse (Survey 2). Points represent individual fish. Boxplots represent the median, lower and upper quartile values, and 1.5 -fold the interquartile range. Yellow, blue and grey points indicate expression is significantly femalebiased, male-biased, and non-significantly different, respectively. Letters denote a significant difference in distribution between groups and ' $a$ ' indicates overall significance without significant pairwise differences. Sample sizes: bluehead wrasse $n=3$ all groups; spotty wrasse socially induced (continued on next page...) Full-size $₫$ DOI: 10.7717/peerj.7032/fig-8 
Figure 8 (...continued)

to change sex in captivity C BF D0 $n=5, \mathrm{C} \mathrm{BF} n=16, \mathrm{M} \mathrm{BF} n=4, \mathrm{ET} n=20, \mathrm{MT} n=1, \mathrm{LT} n=1$, TP $n=11$; IP $n=5$, spotty wrasse opportunistically caught $\operatorname{NBF} n=6$, ET $n=2, \operatorname{MT} n=2, \operatorname{LT} \mathrm{n}=3$, TP $n=1$; kyusen wrasse NBF $n=6$, ET $n=5$, TP $n=7$, IP $n=4$. Abbreviations: C BF D0, breeding female from control tank (TP male present) experimental day 0 ; C BF, breeding female from control tank (TP male present) removed at progressive time points throughout the experiment; CF, control female; ET, early transitional; IP, initial phase male; LT, late transitional; M BF, breeding female from manipulated tanks (TP male removed) removed at progressive time points throughout experiment; MT, mid transitional; NBF, non-breeding female; S1-6, stages 1-6; TP, terminal phase male. See Fig. 1 legend for photo credits of female and male bluehead, spotty and kyusen wrasses.

\section{Brain: cyp19a1b}

For all three species, sex did not have a significant effect on cyp19a1b expression (bluehead wrasse: $X^{2}(8)=13.64, p=0.09$, spotty experiment: $X^{2}(7)=2.88, p=0.90$, spotty survey: $X^{2}(4)=3.13, p=0.54$, kyusen wrasse: $X^{2}(3)=3.00, p=0.28$ ) (Fig. 8). However, in the bluehead wrasse a subtle trend is evident similar to that of cyp19a1a expression in the gonad; expression peaks transiently at stage 1 (median 1.8 fold higher than $\mathrm{CF}$ ), then decreases at stage 2 (median 0.3 -fold that of $\mathrm{CF}$ ), remaining at low levels at subsequent sex change stages and in TP (median 0.4-fold that of CF) and IP males (median 0.3-fold that of CF). No clear trends in cyp19a1b expression were evident in brain samples from spotty or kyusen wrasses.

\section{Brain: it}

In bluehead wrasse, sex did have a significant effect on it expression $\left(X^{2}(8)=18.12\right.$, $p<0.05)$. However, post hoc analysis showed no significant differences between individual sex stages. There was a trend of increasing it expression in fore/midbrain of bluehead wrasse, beginning at stage 1 (median 2-fold higher than $\mathrm{CF}$ ) and progressively increasing to highest levels in TP males (median 3-fold higher than CF). IP male it expression was similar to that of control females (median 1.1-fold higher than CF). In spotty and kyusen wrasses, sex did not have a significant effect on it expression (spotty experiment: $X^{2}(7)=2.82$, $p=0.90$, spotty survey: $X^{2}(4)=4.00, p=0.98$, kyusen wrasse: $X^{2}(3)=1.87, p=0.60$ ), nor were there any clear trends.

\section{DISCUSSION}

In order to understand sex change from a functional and evolutionary standpoint, an important question is to what degree genetic systems regulating sex change are conserved or different among species. Using a comparative qPCR approach across three wrasse species which share protogyny as an ancestral state, we investigated the roles of cyp19a1a and amh as proximal regulators of gonadal sex change, and cyp19a1b and it as regulators of behavioural sex change in the brain. We evaluate whether these genes may form part of a conserved molecular machinery underlying protogynous sex change in wrasses, and whether any differences exist among tropical and temperate species differing in the seasonality of sex change and the rigidity of social hierarchies. 


\section{Gonadal sex change-cyp19a1a and amh as proximal regulators}

In protogynous hermaphrodites, interrupted cyp19a1a expression has been suggested as the molecular switch that initiates ovarian atresia and gonadal sex change (Todd et al., 2016; Liu et al., 2016). Experimental studies have shown that treatment of adult females with aromatase inhibitors can induce complete sex change, both in year-round (Higa et al., 2003; Nozu, Kojima \& Nakamura, 2009) and seasonal (Bhandari et al., 2005; Kroon \& Liley, 2000; Li et al., 2006) breeders. However, whether cyp19a1a downregulation acts as a proximal switch initiating natural gonadal sex change broadly in protogynous species has been unclear. Firstly, because prior studies in other species have not examined atretic ovaries from females during earliest sex change, i.e., before proliferation of male tissues, they could not confirm whether cyp19a1a downregulation occurs coincidentally with the initiation of gonadal sex change in year-round (Zhang et al., 2008; Liu, Guiguen \& Liu, 2009) and seasonal (Li et al., 2006; Huang et al., 2009) breeders. Secondly, in seasonally-breeding species where sex change proceeds from an already regressed ovary with lower oestrogen production and aromatase activity ( Li, Liu \& Lin, 2007), cyp19a1a downregulation may be less important.

In the tropical bluehead wrasse, cyp19a1a expression dropped to near zero at the first signs of ovarian atresia before the presence of male tissues (Fig. 7A). Our spotty and kyusen wrasse samples include early transitioning females with advanced ovarian atresia prior to the appearance of male tissues (ET stage). In spotty wrasse socially manipulated to change sex in captivity, cyp19a1a mRNA levels in ET ovaries are intermediate to those of control breeding females and males (Fig. 7C). In both species caught from the wild, cyp19a1a mRNA levels in ET ovaries are within the range recorded for non-breeding females (Figs. 7E and 7G). Therefore, in these temperate species cyp19a1a expression is already low prior to sex change. This is expected, given the seasonal ovarian atresia that occurs in temperate protogynous hermaphrodites following the breeding season, and that precedes sex change (Li, Liu \& Lin, 2007). Overall, our results confirm that suppression of cyp19a1 a expression is a prerequisite feature of ovaries prior to sex change in protogynous wrasses. Although cyp19ala downregulation may act as a proximal trigger for sex change in tropical year-round breeders like the bluehead wrasse, already low cyp19a1a expression in non-breeding ovaries of temperate species may prime them for sex change. As a result, for temperate wrasses that breed seasonally, reduced aromatase expression is not a conclusive marker to distinguish early stage sex changers from non-breeding females with atretic ovaries. Due to this seasonal atresia, care should also be taken when delineating early sex changers and non-breeding individuals with atretic ovaries.

Amh is an important regulator of male phenotype in fishes, regulating germ cell proliferation and differentiation in the testis of numerous species (Pfennig, Standke \& Gutzeit, 2015; Schulz et al., 2010; Pala et al., 2008; Miura et al., 2002). Our data indicate that $a m h$ is upregulated during sex change with significantly greater amh expression evident in TP males compared to that of females in all three wrasses (Figs. 7B, 7D, 7F and $7 \mathrm{H})$. Testicular production of Amh occurs primarily in Sertoli cells surrounding type A undifferentiated spermatogonia, where it suppresses germ cell proliferation and differentiation as well as steroidogenesis in the interstitial Leydig cells (Pfennig, Standke 
\& Gutzeit, 2015; Skaar et al., 2011). As such, amh expression may be expected to increase with spermatogonial recruitment during sex change. In tropical wrasses, spermatogonia proliferate from stage 4 (Nakamura et al., 1989) and in a recent study of three-spot wrasse (Halichoeres trimaculatus) induced to change sex via aromatase inhibition, amh was first upregulated in stage 4 gonads (Horiguchi et al., 2018). In the current study, amh was also upregulated concurrently with the appearance of male tissues in temperate spotty wrasse (MT stage, equivalent to stage 4) (Figs. 7D and 7F), although timing was inconclusive in kyusen wrasse due to the lack of MT samples (Fig. 7H). By contrast, in bluehead wrasse amh was clearly upregulated prior to the appearance of male cells, at the first sign of ovarian atresia (stage 2, Fig. 7B). Together, these data strongly suggest amh promotes testicular formation and spermatogenesis during protogynous sex change in wrasses, but also implicate amh in initiating maleness in some wrasse species.

In all three wrasses, amh was upregulated coincidentally with the downregulation of cyp19a1a at early sex change from IP female to TP male (Fig. 7). An inverse relationship between amh and cyp19ala expression is widely reported in fishes (Pfennig, Standke \& Gutzeit, 2015), including zebrafish (Danio rerio) (Rodríguez-Marí et al., 2005; Wang \& Orban, 2007), Japanese flounder (Paralichthys olivaceus) (Kitano et al., 2007), pejerrey (Odontesthes bonariensis) (Fernandino et al., 2008), Southern flounder (Paralichthys lethostigma) (Mankiewicz et al., 2013) and rainbow trout (Oncorhynchus mykiss) (Vizziano et al., 2008). Together, these data suggest a bidirectional antagonism between $a m h$ and cyp19a1 a may operate to control sexual fate in fishes (Todd et al., 2016), presumably acting within a broader antagonistic framework between core feminising (e.g., cyp19a1a, foxl2, wnt4) and masculinising (e.g., $d m r t 1, \operatorname{sox} 9, a m h)$ gene networks known to be responsible for directing and maintaining sexual fate in vertebrates (Herpin \& Schartl, 2011b).

\section{Aromatase and isotocin in the brain}

In species where sex change is socially cued, complex neurochemical changes in the brain presumably translate visual social information into behavioural and reproductive responses necessary for sex change. Prior work has identified several neuropeptides as likely regulators of behavioural sex change in social tropical wrasses, including arginine vasotocin, Cyp19a1b, It, and gonadotropin-releasing hormone (reviewed in Lamm et al., 2015; Larson, 2010; Godwin, 2010).

Our data do not strongly support a prominent role for cyp19a1b in initiating behavioural sex change in protogynous wrasses. In spotty and kyusen wrasses, cyp19a1b expression was neither sex-specific nor showed any clear trend across sex change. In bluehead wrasse, although cyp19a1b expression clearly decreased with sex change, the trend was non-significant and only noticeable from stage 2 , after behavioural changes first occur at stage 1. Likewise, Black et al. (2011) found whole brain aromatase activity declined only after behavioural changes in female-to-male sex change of the bluebanded goby (Lythrypnus dalli). Expression of cyp19a1b in bluehead wrasse fore/midbrain closely parallels gonadal cyp19a1a mRNA levels, and may reflect peripheral changes in E2 via putative oestrogen response elements in the cyp19a1b promotor (Diotel et al., 2010). However, exogenous E2 treatment of bluehead wrasse stimulated brain cyp19a1b expression and prevented 
behavioural sex change under socially permissive conditions (Marsh-Hunkin et al., 2013). Brain gene expression patterns are highly heterogeneous and it remains possible that localised cyp19a1b expression changes are important, but would not be detected in studies at a whole brain or fore/midbrain level.

Our data supports the role isotocin plays in modulating teleost socio-sexual behaviours, and social dominance hierarchies in particular (Godwin \& Thompson, 2012; Lema, Sanders \& Walti, 2015; Almeida et al., 2012). In bluehead wrasse, it expression is TP male biased and upregulated across sex change, beginning with a median 2-fold increase at stage 1 when behavioural changes first occur. In tropical wrasses, stage 1 is characterised by rapid (minutes to hours) increases in aggression and male-typical courtship behaviours in transitioning females (Warner \& Swearer, 1991) that are presumably critical for establishing dominance as the new TP male before gonadal sex change ensues. In wrasses generally, IP males mimic female behaviour and colouration to avoid TP male aggression. We found that it expression was as low in bluehead IP males as in females. This further indicates a role for it in establishing the dominant TP male phenotype. Our qPCR data validate the same patterns reported in recent whole-transcriptome analyses in this species (Todd et al., 2017). An opposite pattern for it was observed in the bluebanded goby, a bidirectional hermaphrodite in which high social status is also a critical cue for female-male sex change, yet the number of isotocin-immunoreactive cells in the pre-optic area decreased across female-male sex change (Black, Reavis \& Grober, 2004). These data and studies in social cichlids indicate isotocin can have species-specific and context-dependent roles in social behaviour (Reddon et al., 2017; O'connor et al., 2015; O'connor et al., 2016).

Expression of it was not associated with sexual phenotype or sex change in spotty or kyusen wrasses. Although our social manipulation experiment provides the first evidence confirming sex change is socially cued in spotty wrasse, behavioural markers of sex change have not been characterised in either species. Overall, our data and those of Black, Reavis $\&$ Grober (2004) support isotocin as an important proximal mediator of behavioural transitions in sequential hermaphrodites with strict social hierarchies. Further work is necessary to clarify whether it also regulates socially-cued sex change in temperate wrasses, and may show seasonal fluctuations.

\section{CONCLUSIONS}

This research investigated whether evolutionarily conserved molecular mechanisms underlie protogynous sex change in wrasses. In this first comparison of candidate gene expression in tropical versus temperate protogynous species, we find both conservation and diversity in the regulatory machinery underlying sex change. Our data support conserved roles for cyp19a1a and amh as important proximal regulators of gonadal sex change in protogynous wrasses - these genes may act concurrently to orchestrate the ovary-testis transition by controlling ovarian atresia and testicular development, respectively. However, differences in timing of expression changes relative to key histological events of sex change may be species-specific or reflect differences between tropical and temperate species in the seasonality or duration of sex change. In the brain, our data do not support a role for brain 
aromatase, cyp19a1b, in initiating behavioural sex change, as expression changes for this gene trailed rapid behavioural changes. Brain isotocin expression strongly correlated with TP male-specific behaviours and the rapid behavioural changes characterising the onset of sex change in the bluehead wrasse, but not spotty or kyusen wrasses. Characterising behavioural and molecular markers of sex change in temperate wrasses will be important for understanding how visual social cues are transduced to initiate the sex change cascade. Future work employing macro-dissection of the brain will be important, as our sampling of the whole brain or fore/midbrain may have obscured important region-specific signals. Future manipulative experiments will also be important in determining specific functions of these genes in regulating sex change.

\section{ACKNOWLEDGEMENTS}

We are grateful to Carlos Farias Moraes and Holly Robertson for their invaluable assistance in conducting the captive experiments in spotty wrasse. We thank Bill Tylor, Sidney Gaston Sanchez, Brandon Klapheke, Jeannie Brady, and Alison Lukowsky for support collecting bluehead samples. Robbie McPhee assisted with the preparation of figures. Alexander Goikoetxea provided valuable feedback on an earlier draft. Vikram Baliga generously supplied data for the phylogenetic analyses.

\section{ADDITIONAL INFORMATION AND DECLARATIONS}

\section{Funding}

This work was supported by the Royal Society of New Zealand Marsden Fund (UOO1308 to Neil J. Gemmell), the Japan Society for the Promotion of Science (L10703 to P Mark Lokman) and the National Science Foundation (1257791 to John R. Godwin and 1257761 to Bill Tyler at Indian River State College, Florida). Jodi Thomas was supported by an Otago School of Medical Science Summer Scholarship. The funders had no role in study design, data collection and analysis, decision to publish, or preparation of the manuscript.

\section{Grant Disclosures}

The following grant information was disclosed by the authors:

Royal Society of New Zealand Marsden Fund: UOO1308.

Japan Society for the Promotion of Science: L10703.

National Science Foundation: 1257791.

Indian River State College: 1257761.

Otago School of Medical Science Summer Scholarship.

\section{Competing Interests}

The authors declare there are no competing interests.

\section{Author Contributions}

- Jodi T. Thomas conceived and designed the experiments, performed the experiments, analyzed the data, prepared figures and/or tables, authored or reviewed drafts of the paper, approved the final draft, wrote the manuscript. 
- Erica V. Todd conceived and designed the experiments, analyzed the data, prepared figures and/or tables, authored or reviewed drafts of the paper, approved the final draft, wrote the manuscript.

- Simon Muncaster conceived and designed the experiments, performed the experiments, authored or reviewed drafts of the paper, approved the final draft.

- P Mark Lokman conceived and designed the experiments, performed the experiments, authored or reviewed drafts of the paper, approved the final draft.

- Erin L. Damsteegt performed the experiments, authored or reviewed drafts of the paper, approved the final draft.

- Hui Liu performed the experiments, approved the final draft.

- Kiyoshi Soyano conceived and designed the experiments, performed the experiments, approved the final draft.

- Florence Gléonnec and Melissa S. Lamm performed the experiments, approved the final draft.

- John R. Godwin conceived and designed the experiments, performed the experiments, approved the final draft.

- Neil J. Gemmell conceived and designed the experiments, authored or reviewed drafts of the paper, approved the final draft.

\section{Animal Ethics}

The following information was supplied relating to ethical approvals (i.e., approving body and any reference numbers):

The Institutional Animal Care and Use Committee at North Carolina State University provided approval for Experiment 1 (12-069-0). The New Zealand National Animal Ethics Advisory Committee provided approval for Experiment 2 (2015_02) and Survey 1 (92-10). The Animal Care and Use Committee of the Institute for East China Sea Research, Nagasaki University, Japan, provided approval for Survey 2 (\#15-06).

\section{Field Study Permissions}

The following information was supplied relating to field study approvals (i.e., approving body and any reference numbers):

Fish were collected with approval from the New Zealand Ministry of Primary Industries (593-3).

\section{DNA Deposition}

The following information was supplied regarding the deposition of DNA sequences:

Candidate gene and reference gene sequences described here are accessible via GenBank accession numbers: bluehead wrasse cyp19a1a MK252274, amh MK252275, cyp19a1b MK252276, it MF279538.1, g6pd MK252277, ef1a MF279537.1, 18S MK246126, spotty wrasse cyp19a1a MK252278, amh MK252279, cyp19a1b MK252280, it MK252281, g6pd MK252282, ef1a MK252283, 18S MK246127, kyusen wrasse cyp19a1a MK252284, amh MK252285, cyp19a1b MK252286, it MK252287, g6pd MK252288, ef1a MK252289, 18 S MK246128. 


\section{Data Availability}

The following information was supplied regarding data availability:

$\mathrm{R}$ code for statistical analysis of qPCR data is available in Data S1. Raw qPCR measurements are available in Data S2. Raw (.raw) and relative (.rel) expression values are provided in separate sheets for each species, and for brain and gonad analyses separately. The sequence alignment used for phylogenetic analyses is available in Data S3. The file contains a Nexus format alignment of concatenated $12 \mathrm{~S}$ and $16 \mathrm{~S}$ ribosomal RNA sequence data.

\section{Supplemental Information}

Supplemental information for this article can be found online at http://dx.doi.org/10.7717/ peerj.7032\#supplemental-information.

\section{REFERENCES}

Almeida O, Gozdowska M, Kulczykowska E, Oliveira RF. 2012. Brain levels of argininevasotocin and isotocin in dominant and subordinate males of a cichlid fish. Hor mones and Behaviour 61(2):212-217 DOI 10.1016/j.yhbeh.2011.12.008.

Baliga VB, Law CJ. 2016. Cleaners among wrasses: phylogenetics and evolutionary patterns of cleaning behavior within Labridae. Molecular Phylogenetics and Evolution 94:424-435 DOI 10.1016/j.ympev.2015.09.006.

Bhandari RK, Alam MA, Higa M, Soyano K, Nakamura M. 2005. Evidence that estrogen regulates the sex change of honeycomb grouper (Epinephelus merra), a protogynous hermaphrodite fish. Journal of Experimental Zoology Part A: Comparative Experimental Biology 303(6):497-503 DOI 10.1002/jez.a.178.

Bhandari RK, Komuro H, Nakamura S, Higa M, Nakamura M. 2003. Gonadal restructuring and correlative steroid hormone profiles during natural sex change in protogynous honeycomb grouper (Epinephelus merra). Zoological Science 20(11):1399-1404 DOI 10.2108/zsj.20.1399.

Black MP, Balthazart J, Baillien M, Grober MS. 2011. Rapid increase in aggressive behavior precedes the decrease in brain aromatase activity during socially mediated sex change in Lythrypnus dalli. General and Comparative Endocrinology 170(1):119-124 DOI 10.1016/j.ygcen.2010.09.019.

Black MP, Reavis RH, Grober MS. 2004. Socially induced sex change regulates forebrain isotocin in Lythrypnus dalli. Neuroreport 15(1):185-189

DOI 10.1097/00001756-200401190-00036.

Casas L, Saborido-Rey F, Ryu T, Michell C, Ravasi T, Irigoien X. 2016. Sex change in clownfish: molecular insights from transcriptome analysis. Scientific Reports 6:35461 DOI 10.1038/srep35461.

Chen S, Zhang G, Shao C, Huang Q, Liu G, Zhang P, Song W, An N, Chalopin D, Volff J-N. 2014. Whole-genome sequence of a flatfish provides insights into ZW sex chromosome evolution and adaptation to a benthic lifestyle. Nature Genetics 46(3):253-260 DOI 10.1038/ng.2890. 
Cowman PF, Bellwood DR, Van Herwerden L. 2009. Dating the evolutionary origins of wrasse lineages (Labridae) and the rise of trophic novelty on coral reefs. Molecular Phylogenetics and Evolution 52(3):621-631 DOI 10.1016/j.ympev.2009.05.015.

Darriba D, Taboada GL, Doallo R, Posada D. 2012. JModelTest 2: more models, new heuristics and parallel computing. Nature Methods 9(8):772.

Devlin RH, Nagahama Y. 2002. Sex determination and sex differentiation in fish: an overview of genetic, physiological, and environmental influences. Aquaculture 208(3):191-364 DOI 10.1016/S0044-8486(02)00057-1.

Diotel N, Le Page Y, Mouriec K, Tong S-K, Pellegrini E, Vaillant C, Anglade I, Brion F, Pakdel F, Chung B-C. 2010. Aromatase in the brain of teleost fish: expression, regulation and putative functions. Frontiers in Neuroendocrinology 31(2):172-192 DOI 10.1016/j.yfrne.2010.01.003.

Donaldson ZR, Young LJ. 2008. Oxytocin, vasopressin, and the neurogenetics of sociality. Science 322(5903):900-904 DOI 10.1126/science.1158668.

Erisman BE, Petersen CW, Hastings PA, Warner RR. 2013. Phylogenetic perspectives on the evolution of functional hermaphroditism in teleost fishes. Integrative and Comparative Biology 53(4):736-754 DOI 10.1093/icb/ict077.

Fernandino JI, Hattori RS, Kimura H, Strüssmann CA, Somoza GM. 2008. Expression profile and estrogenic regulation of Anti-Müllerian hormone during gonadal development in pejerrey Odontesthes bonariensis, a teleost fish with strong temperaturedependent sex determination. Developmental Dynamics 237(11):3192-3199 DOI 10.1002/dvdy.21731.

Gemmell NJ, Akiyama S. 1996. An efficient method for the extraction of DNA from vertebrate tissues. Trends in Genetics 12(9):338-339

DOI 10.1016/S0168-9525(96)80005-9.

Godwin J. 2010. Neuroendocrinology of sexual plasticity in teleost fishes. Frontiers in Neuroendocrinology 31(2):203-216 DOI 10.1016/j.yfrne.2010.02.002.

Godwin J, Thompson R. 2012. Nonapeptides and social behavior in fishes. Hormones and Behaviour 61(3):230-238 DOI 10.1016/j.yhbeh.2011.12.016.

Goodson JL, Bass AH. 2000. Forebrain peptides modulate sexually polymorphic vocal circuitry. Nature 403(6771):769-772 DOI 10.1038/35001581.

Guiguen Y, Fostier A, Piferrer F, Chang C-F. 2010. Ovarian aromatase and estrogens: a pivotal role for gonadal sex differentiation and sex change in fish. General and Comparative Endocrinology 165(3):352-366 DOI 10.1016/j.ygcen.2009.03.002.

Hattori RS, Murai Y, Oura M, Masuda S, Majhi SK, Sakamoto T, Fernandino JI, Somoza GM, Yokota M, Strüssmann CA. 2012. A Y-linked Anti-Müllerian hormone duplication takes over a critical role in sex determination. Proceedings of the National Academy of Sciences of the United States of America 109(8):2955-2959 DOI 10.1073/pnas.1018392109.

Hellmann JK, Reddon AR, Ligocki IY, O’Connor CM, Garvy KA, Marsh-Rollo SE, Hamilton IM, Balshine S. 2015. Group response to social perturbation: impacts of isotocin and the social landscape. Animal Behaviour 105:55-62 DOI 10.1016/j.anbehav.2015.03.029. 
Herpin A, Schartl M. 2011a. Dmrtl genes at the crossroads: a widespread and central class of sexual development factors in fish. The FEBS Journal 278(7):1010-1019 DOI 10.1111/j.1742-4658.2011.08030.x.

Herpin A, Schartl M. 2011b. Sex determination: switch and suppress. Current Biology 21(17):R656-R9 DOI 10.1016/j.cub.2011.07.026.

Higa M, Ogasawara K, Sakaguchi A, Nagahama Y, Nakamura M. 2003. Role of steriod hormones in sex change of protogynous wrasse. Fish Physiology and Biochemistry 28(1-4):149-150 DOI 10.1023/B:FISH.0000030505.28138.d1.

Horiguchi R, Nozu R, Hirai T, Kobayashi Y, Nakamura M. 2018. Expression patterns of sex differentiation-related genes during gonadal sex change in the protogynous wrasse, Halichoeres trimaculatus. General and Comparative Endocrinology 257:67-73 DOI 10.1016/j.ygcen.2017.06.017.

Hu Q, Guo W, Gao Y, Tang R, Li D. 2015. Molecular cloning and characterization of amh and dax 1 genes and their expression during sex inversion in rice-field eel Monopterus albus. Scientific Reports 5:16667 DOI 10.1038/srep16667.

Huang W, Zhou L, Li Z, Gui J-F. 2009. Expression pattern, cellular localization and promoter activity analysis of ovarian aromatase (Cyp19a1a) in protogynous hermaphrodite red-spotted grouper. Molecular and Cellular Endocrinology 307(1):224-236 DOI 10.1016/j.mce.2009.04.003.

Jones G. 1980. Growth and reproduction in the protogynous hermaphrodite Pseudolabrus celidotus (Pisces: Labridae) in New Zealand. Copeia 4:660-675.

Josso N, Di Clemente N, Gouédard L. 2001. Anti-Müllerian hormone and its receptors. Molecular and Cellular Endocrinology 179(1):25-32 DOI 10.1016/S0303-7207(01)00467-1.

Kamiya T, Kai W, Tasumi S, Oka A, Matsunaga T, Mizuno N, Fujita M, Suetake H, Suzuki S, Hosoya S. 2012. A trans-species missense SNP in Amhr2 is associated with sex determination in the tiger pufferfish, Takifugu rubripes (fugu). PLOS Genetics 8(7):e1002798 DOI 10.1371/journal.pgen.1002798.

Kazancioğlu E, Alonzo SH. 2010. A comparative analysis of sex change in Labridae supports the size advantage hypothesis. Evolution 64(8):2254-2264.

Kearse M, Moir R, Wilson A, Stones-Havas S, Cheung M, Sturrock S, Buxton S, Cooper A, Markowitz S, Duran C. 2012. Geneious Basic: an integrated and extendable desktop software platform for the organization and analysis of sequence data. Bioinformatics 28(12):1647-1649 DOI 10.1093/bioinformatics/bts199.

Kitano T, Yoshinaga N, Shiraishi E, Koyanagi T, Abe SI. 2007. Tamoxifen induces masculinization of genetic females and regulates P450 aromatase and Müllerian inhibiting substance mRNA expression in Japanese flounder (Paralichthys olivaceus). Molecular Reproduction and Development 74(9):1171-1177 DOI 10.1002/mrd.20603.

Kroon FJ, Liley NR. 2000. The role of steroid hormones in protogynous sex change in the blackeye goby, Coryphopterus nicholsii (Teleostei: Gobiidae). General and Comparative Endocrinology 118(2):273-283 DOI 10.1006/gcen.2000.7459. 
Lamm MS, Liu H, Gemmell NJ, Godwin JR. 2015. The need for speed: neuroendocrine regulation of socially-controlled sex change. Integrative and Comparative Biology 55(2):307-322 DOI 10.1093/icb/icv041.

Larson ET. 2010. Neuroendocrine regulation in sex-changing fishes. In: Hormones and reproduction of vertebrates. Vol. 1. Cambridge, Massachusetts: Academic Press, 149-168.

Larson E, Norris D, Summers C. 2003. Monoaminergic changes associated with socially induced sex reversal in the saddleback wrasse. Neuroscience 119(1):251-263 DOI 10.1016/S0306-4522(03)00119-2.

Lee YH, Du JL, Yueh WS, Lin BY, Huang JD, Lee CY, Lee M-F, Lau E-L, Lee F-Y, Morrey C. 2001. Sex change in the protandrous black porgy, Acanthopagrus schlegeli: a review in gonadal development, estradiol, estrogen receptor, aromatase activity and gonadotropin. Journal of Experimental Zoology Part A: Ecological Genetics and Physiology 290(7):715-726 DOI 10.1002/jez.1122.

Lema SC, Sanders KE, Walti KA. 2015. Arginine vasotocin, isotocin and nonapeptide receptor gene expression link to social status and aggression in sex-dependent patterns. Journal of Neuroendocrinology 27(2):142-157 DOI 10.1111/jne.12239.

Li GL, Liu XC, Lin HR. 2007. Seasonal changes of serum sex steroids concentration and aromatase activity of gonad and brain in red-spotted grouper (Epinephelus akaara). Animal Reproductive Science 99(1-2):156-166 DOI 10.1016/j.anireprosci.2006.05.015.

Li GL, Liu XC, Zhang Y, Lin HR. 2006. Gonadal development, aromatase activity and $\mathrm{P} 450$ aromatase gene expression during sex inversion of protogynous redspotted grouper Epinephelus akaara (Temminck and Schlegel) after implantation of the aromatase inhibitor, fadrozole. Aquaculture Research 37(5):484-491 DOI 10.1111/j.1365-2109.2005.01453.x.

Li M, Sun Y, Zhao J, Shi H, Zeng S, Ye K, Jiang D, Zhou L, Sun L, Tao W. 2015. A tandem duplicate of Anti-Müllerian hormone with a missense SNP on the Y chromosome is essential for male sex determination in Nile Tilapia, Oreochromis niloticus. PLOS Genetics 11(11):e1005678 DOI 10.1371/journal.pgen.1005678.

Liu J-F, Guiguen Y, Liu S-J. 2009. Aromatase (P450arom) and $11 \beta$-hydroxylase $(\mathrm{P} 45011 \beta)$ genes are differentially expressed during the sex change process of the protogynous rice field eel, Monopterus albus. Fish Physiololgy and Biochemistry 35(3):511-518 DOI 10.1007/s10695-008-9255-9.

Liu H, Lamm MS, Rutherford K, Black MA, Godwin JR, Gemmell NJ. 2015. Large-scale transcriptome sequencing reveals novel expression patterns for key sex-related genes in a sex-changing fish. Biology of Sex Differences 6(1):1-20 DOI 10.1186/s13293-014-0019-1.

Liu H, Todd EV, Lokman MP, Lamm MS, Godwin JR, Gemmell NJ. 2016. Sexual plasticity: a fishy tale. Molecular Reproduction and Development 84:171-194.

Mank JE, Promislow DE, Avise JC. 2006. Evolution of alternative sex-determining mechanisms in teleost fishes. Biological Journal of the Linnean Society 87(1):83-93 DOI 10.1111/j.1095-8312.2006.00558.x. 
Mankiewicz JL, Godwin J, Holler BL, Turner PM, Murashige R, Shamey R, Daniels HV, Borski RJ. 2013. Masculinizing effect of background color and cortisol in a flatfish with environmental sex-determination. Integrative and Comparative Biology 53(4):755-765 DOI 10.1093/icb/ict093.

Marsh-Hunkin KE, Heinz HM, Hawkins MB, Godwin J. 2013. Estrogenic control of behavioral sex change in the bluehead wrasse, Thalassoma bifasciatum. Integrative and Comparative Biology 53(6):951-959 DOI 10.1093/icb/ict096.

Matsuda M, Nagahama Y, Shinomiya A, Sato T, Matsuda C, Kobayashi T, Morrey CE, Shibata N, Asakawa S, Shimizu N. 2002. DMY is a Y-specific DM-domain gene required for male development in the medaka fish. Nature 417(6888):559-563 DOI 10.1038/nature751.

Miura T, Miura C, Konda Y, Yamauchi K. 2002. Spermatogenesis-preventing substance in Japanese eel. Development 129(11):2689-2697.

Muncaster S, Norberg B, Andersson E. 2013. Natural sex change in the temperate protogynous Ballan wrasse Labrus bergylta. Journal of Fish Biology 82(6):1858-1870 DOI 10.1111/jfb.12113.

Munday PL, Buston PM, Warner RR. 2006. Diversity and flexibility of sex-change strategies in animals. Trends in Ecology \& Evolution 21(2):89-95

DOI 10.1016/j.tree.2005.10.020.

Nakamura M, Hourigan TF, Yamauchi K, Nagahama Y, Grau EG. 1989. Histological and ultrastructural evidence for the role of gonadal steroid hormones in sex change in the protogynous wrasse Thalassoma duperrey. Environmental Biology of Fishes 24(2):117-136 DOI 10.1007/BF00001282.

Nanda I, Kondo M, Hornung U, Asakawa S, Winkler C, Shimizu A, Shan Z, Haaf T, Shimizu N, Shima A. 2002. A duplicated copy of DMRT1 in the sex-determining region of the $\mathrm{Y}$ chromosome of the medaka, Oryzias latipes. Proceedings of the National Academy of Sciences of the United States of America 99(18):11778-11783 DOI 10.1073/pnas.182314699.

Nozu R, Horiguchi R, Kobayashi Y, Nakamura M. 2015. Expression profile of doublesex/male abnormal-3-related transcription factor-1 during gonadal sex change in the protogynous wrasse, Halichoeres trimaculatus. Molecular Reproduction and Development 82(11):859-866 DOI 10.1002/mrd.22527.

Nozu R, Kojima Y, Nakamura M. 2009. Short term treatment with aromatase inhibitor induces sex change in the protogynous wrasse, Halichoeres trimaculatus. General and Comparative Endocrinology 161(3):360-364 DOI 10.1016/j.ygcen.2009.01.024.

O’Connell LA, Hofmann HA. 2011. Genes, hormones, and circuits: an integrative approach to study the evolution of social behavior. Frontirs in Neuroendocrinology 32(3):320-335 DOI 10.1016/j.yfrne.2010.12.004.

O'Connell LA, Matthews BJ, Hofmann HA. 2012. Isotocin regulates paternal care in a monogamous cichlid fish. Hormones and Behaviour 61(5):725-733 DOI 10.1016/j.yhbeh.2012.03.009.

O'connor CM, Marsh-Rollo SE, Aubin-Horth N, Balshine S. 2016. Species-specific patterns of nonapeptide brain gene expression relative to pair-bonding behavior 
in grouping and non-grouping cichlids. Hormones and Behaviour 80:30-38 DOI 10.1016/j.yhbeh.2015.10.015.

O'connor CM, Marsh-Rollo SE, Ghio SC, Balshine S, Aubin-Horth N. 2015. Is there convergence in the molecular pathways underlying the repeated evolution of sociality in African cichlids? Hormones and Behaviour 75:160-168 DOI 10.1016/j.yhbeh.2015.07.008.

Pala I, Klüver N, Thorsteinsdóttir S, Schartl M, Coelho MM. 2008. Expression pattern of Anti-Müllerian hormone (amh) in the hybrid fish complex of Squalius alburnoides. Gene 410(2):249-258 DOI 10.1016/j.gene.2007.12.018.

Pfennig F, Standke A, Gutzeit HO. 2015. The role of Amh signaling in teleost fishmultiple functions not restricted to the gonads. General and Comparative Endocrinology 223:87-107 DOI 10.1016/j.ygcen.2015.09.025.

R Core Team. 2014. R: a language and environment for statistical computing. Vienna: R Foundation for Statistical Computing.

Reddon AR, Balshine S, O'Connor CM, Voisin MR. 2014. Isotocin and sociality in the cooperatively breeding cichlid fish, Neolamprologus pulcher. Behaviour 151(10):1389-1411 DOI 10.1163/1568539X-00003190.

Reddon AR, O'Connor CM, Marsh-Rollo SE, Balshine S. 2012. Effects of isotocin on social responses in a cooperatively breeding fish. Animal Behaviour 84(4):753-760 DOI 10.1016/j.anbehav.2012.07.021.

Reddon AR, O'Connor CM, Nesjan E, Cameron J, Hellmann JK, Ligocki IY, MarshRollo SE, Hamilton IM, Wylie DR, Hurd PL. 2017. Isotocin neuronal phenotypes differ among social systems in cichlid fishes. Royal Society Open Science 4(5):Article 170350 DOI 10.1098/rsos.170350.

Rodríguez-Marí A, Yan Y-L, BreMiller RA, Wilson C, Canestro C, Postlethwait JH. 2005. Characterization and expression pattern of zebrafish Anti-Müllerian hormone (Amh) relative to sox9a, sox9b, and cyp19a1a, during gonad development. Gene Expression Patterns 5(5):655-667 DOI 10.1016/j.modgep.2005.02.008.

Ronquist F, Huelsenbeck JP. 2003. MrBayes 3: Bayesian phylogenetic inference under mixed models. Bioinformatics 19(12):1572-1574 DOI 10.1093/bioinformatics/btg180.

Schulz RW, De França LR, Lareyre J-J, LeGac F, Chiarini-Garcia H, Nobrega RH, Miura T. 2010. Spermatogenesis in fish. General and Comparative Endocrinology 165(3):390-411 DOI 10.1016/j.ygcen.2009.02.013.

Sekido R, Lovell-Badge R. 2013. Genetic control of testis development. Sexual Development 7(1-3):21-32 DOI 10.1159/000342221.

Semsar K, Godwin J. 2003. Social influences on the arginine vasotocin system are independent of gonads in a sex-changing fish. Journal of Neuroscience 23(10):4386-4393 DOI 10.1523/JNEUROSCI.23-10-04386.2003.

Shapiro DY, Lubbock R. 1980. Group sex ratio and sex reversal. Journal of Theoretical Biology 83(3):411-426 DOI 10.1016/0022-5193(80)90048-X.

Siegfried K. 2010. In search of determinants: gene expression during gonadal sex differentiation. Journal of Fish Biology 76(8):1879-1902

DOI 10.1111/j.1095-8649.2010.02594.x. 
Skaar K, Nobrega R, Magaraki A, Olsen L, Schulz R, Male R. 2011. Proteolytically activated, recombinant Anti-Müllerian hormone inhibits androgen secretion, proliferation, and differentiation of spermatogonia in adult zebrafish testis organ cultures. Endocrinology 152(9):3527-3540 DOI 10.1210/en.2010-1469.

Tchoudakova A, Callard GV. 1998. Identification of multiple CYP19 genes encoding different cytochrome P450 aromatase isozymes in brain and ovary 1. Endocrinology 139(4):2179-2189 DOI 10.1210/endo.139.4.5899.

Thompson RR, Walton JC. 2004. Peptide effects on social behavior: effects of vasotocin and isotocin on social approach behavior in male goldfish (Carassius auratus). Behavioural Neuroscience 118(3):620-626 DOI 10.1037/0735-7044.118.3.620.

Todd EV, Liu H, Lamm MS, Thomas JT, Rutherford K, Thompson KC, Godwin JR, Gemmell NJ. 2017. Female mimicry by sneaker males has a transcriptomic signature in both the brain and gonad in a sex changing fish. Molecular Biology and Evolution 35:225-241.

Todd E, Liu H, Muncaster S, Gemmell N. 2016. Bending genders: the biology of natural sex change in fish. Sexual Development 10:223-241 DOI 10.1159/000449297.

Todd EV, Ortega-Recalde O, Liu H, Lamm MS, Rutherford KM, Cross H, Black MA, Kardailsky O, Graves JA, Hore TA, Godwin JR, Gemmell NJ. 2018. Stress, novel sex genes and epigenetic reprogramming orchestrate socially-controlled sex change. bioRxiv DOI 10.1101/481143.

Untergasser A, Cutcutache I, Koressaar T, Ye J, Faircloth BC, Remm M, Rozen SG. 2012. Primer3-new capabilities and interfaces. Nucleic Acids Research 40(15):e115e115 DOI 10.1093/nar/gks596.

Vizziano D, Baron D, Randuineau G, Mahe S, Cauty C, Guiguen Y. 2008. Rainbow trout gonadal masculinization induced by inhibition of estrogen synthesis is more physiological than masculinization induced by androgen supplementation. Biology of Reproduction 78(5):939-946 DOI 10.1095/biolreprod.107.065961.

Wang X, Orban L. 2007. Anti-Müllerian hormone and $11 \beta$-hydroxylase show reciprocal expression to that of aromatase in the transforming gonad of zebrafish males. Developmental Dynamics 236(5):1329-1338 DOI 10.1002/dvdy.21129.

Warner RR. 1984. Mating behavior and hermaphroditism in coral reef fishes. American Scientist 72(2):128-136.

Warner RR, Swearer SE. 1991. Social control of sex change in the bluehead wrasse, Thalassoma bifasciatum (Pisces: Labridae). Biological Bulletin 181:199-204 DOI 10.2307/1542090.

Westneat MW, Alfaro ME. 2005. Phylogenetic relationships and evolutionary history of the reef fish family Labridae. Molecular Phylogenetics and Evolution 36(2):370-390 DOI 10.1016/j.ympev.2005.02.001.

Zhang Y, Zhang W, Yang H, Zhou W, Hu C, Zhang L. 2008. Two cytochrome P450 aromatase genes in the hermaphrodite ricefield eel Monopterus albus: mRNA expression during ovarian development and sex change. Journal of Endocrinology 199(2):317-331 DOI 10.1677/JOE-08-0303. 